\title{
Social media and sensemaking patterns in new product development: demystifying the customer sentiment
}

\author{
Mihalis Giannakis ${ }^{1} \cdot$ Rameshwar Dubey $^{2}$ (D) Shishi Yan $^{3} \cdot$ Konstantina Spanaki ${ }^{4}$ \\ Thanos Papadopoulos 5
}

Published online: 29 August 2020

(c) The Author(s) 2020

\begin{abstract}
Artificial intelligence by principle is developed to assist but also support decision making processes. In our study, we explore how information retrieved from social media can assist decision-making processes for new product development (NPD). We focus on consumers' emotions that are expressed through social media and analyse the variations of their sentiments in all the stages of NPD. We collect data from Twitter that reveal consumers' appreciation of aspects of the design of a newly launched model of an innovative automotive company. We adopt the sensemaking approach coupled with the use of fuzzy logic for text mining. This combinatory methodological approach enables us to retrieve consensus from the data and to explore the variations of sentiments of the customers about the product and define the polarity of these emotions for each of the NPD stages. The analysis identifies sensemaking patterns in Twitter data and explains the NPD process and the associated steps where the social interactions from customers can have an iterative role. We conclude the paper by outlining an agenda for future research in the NPD process and the role of the customer opinion through sensemaking mechanisms.
\end{abstract}

Keywords Social media $\cdot$ New product development (NPD) · Artificial intelligence · Sensemaking · Customer sentiment

\section{Introduction}

The rapid development of Big Data Analytics, Artificial Intelligence (AI) techniques and their associated applications have brought tremendous opportunities to enterprises (George et al. 2016; Zhan et al. 2020; Fosso Wamba and Akter 2019; Duan et al. 2019; Dwivedi et al. 2019; Akter et al. 2019, 2020), but also the need to transform Operations and process management has evolved at the same time (Matthias et al. 2017; Kache and Seuring 2017; Fosso Wamba and Queiroz 2020). The New Product Development (NPD) is one of the strategic cores of enterprise survival and development, and an important focus area in corporate strategy and decision making processes (McCarthy et al. 2006; Gonzalez-Zapatero et al. 2017; Yan

Extended author information available on the last page of the article 
and Wagner 2017). In this ever-changing environment, it is imperative for companies to develop new products meeting the demands of the highly complex, dynamic and unpredictable business environment (Nambisan 2002; Yan and Azadegan 2017), but also foster innovation in the process while targeting operational efficiency (Lam et al. 2016).

In previous decades, NPD was highly reliant on several stages such as market research, product idea creation and product design. The decision-making at each stage was deemed difficult because of the challenges in obtaining information from various involved parties (McCarthy et al. 2006) and often with a significant cost in terms of energy, financial resources and time to make decisions (Ogawa and Piller 2006). In the era of Big Data, Analytical processes and AI, the traditional decision-making process has not kept up with the times; as the evolution of technology provides cheaper and faster decision-making solutions as data are evolving and increasing in volume and formats (Bawack et al. 2019; Feki et al. 2016; Fosso Wamba et al. 2017; Queiroz and Telles 2018; Fosso Wamba et al. 2020), the NPD process should also focus on "making sense" of the data available (Lycett 2013; Wei et al. 2014). The sensemaking process of public views for NPD can utilise feedback and comments from social media and highlight the iterative role of the customer in value co-creation while exploring the sentiment throughout the whole NPD process (Zhan et al. 2018; Du et al. 2016; Fuchs and Schreier 2011; Majumdar and Bose 2019).

Social media provide a new communication path between the enterprise and the directly involved stakeholders in NPD (Chae 2015; Du et al. 2016). Social media, equipped with the latest AI techniques of text mining, could provide unpreceded decision-making opportunities (Duan et al. 2019; Dwivedi et al. 2019). Social media sensemaking processes in operations (Matthias et al. 2017) can reach real-time and common consensus and communication with consumers, opening up a new path for understanding ever-changing consumer demand and building good relationships with them (Hoyer et al. 2010). Also, the communication with customers is deemed as essential (Bahemia et al. 2017), not only for the building external links with the market but also for the support of internal product development teams. Social media applications can run through the entire process of product development (Du et al. 2016; SeeTo and Ngai 2018), from requirements communication, creative generation, product design, prototype testing, product release, product promotion and information feedback to product after-sales service. Consumers can be deeply involved in the NPD cycle (Hoyer et al. 2010), forming a strong relationship with the corporate products, and ultimately reflecting consumer demand for the newly launched products.

Building on a multidisciplinary, combinatory approach of the theoretical and empirical foundations borrowed from Operations and Information Management, we ground our study in the NPD and sensemaking academic fields for the analysis of social media data. We apply the sensemaking approach to explore the customer's perspective and sentiment as they are expressed through social media throughout the stages of NPD. We collect data through an API that we developed to elicit information from Twitter for a specific product from the automotive industry. Through a sentiment analysis that is grounded on fuzzy theory for retrieving consensus from the data, we identify the impact of customer involvement (via the use of social media). This can be reflected through a variety of emotions throughout the NPD process.

Our objective is to contribute to our knowledge on NPD by providing theoretical insights and empirical findings for each stage and our aim to provide a research consensus for the analysis of social media data for NPD processes based on sensemaking patterns (Weick 1995; Weick et al. 2005) of customers' sentiments. To achieve this, we discuss the NPD process and the associated steps where the public opinion can improve the process, and we extend each of these steps by exploring the sensemaking patterns in data retrieved from social 
media. Based on our findings we develop a research agenda for future research, highlighting the iterative role of the customer in the NPD process and the use of social media as a facilitator of these communications. Although previous studies have emphasized the use of marketing intelligence and consumer preferences for the development of new products, our study proposes a novel approach through the use of social media to identify latent product features using a two-level analysis. The proposed sensemaking mechanisms are used through the combination of sentiment analysis and fuzzy mathematics to provide a lens of analysing NPD stages and on a broader scope, various operations and supply chain processes.

The remainder of the paper proceeds as follows. First, we explain the emergence of social media in NPD through an extensive literature review putting social media data strategies on the core of attention alongside the sensemaking perspectives in operations management fields. Building on this, we conceptualise and explore the aspects of the NPD to underpin our investigation of the customer iterations in the whole process. Next, we develop a sensemaking approach through the analysis of social media data (collected for an example product from the automotive industry - 10,210 tweets) providing the views of customers on various stages of NPD.

\section{Theoretical foundations}

The question motivating our study is: What is the impact of the customer sentiment in the steps of the Product Development Process? We aim to uncover insights from social media data of customer views and demystify the sentiment variations during the development process and the associated value for the overall operations.

Following Weick's (1995) prescriptions, we adopt a sensemaking-oriented approach to the analysis of social media data. In particular, we draw on the (commonly) conceptual work in the NPD literature to develop a framing for the analysis of the NPD process in various stages. We analyse the sentiment variations of the customer opinion for a case product (from the automotive industry) for each step of the NPD process, while we explain and discuss the arising sensemaking patterns of customer views for each stage of NPD to improve the products and services. Thus, we provide an initial overview of the overarching theoretical concepts which motivated and supported this study, namely: the process of NPD, customer participation in the NPD, AI, social media and NPD and ultimately the foundations of sensemaking for social and public opinion.

\subsection{Product design and development: the NPD process}

NPD activities constitute a significant source of companies' long-term profits, and sustainable competitive advantage (Van Oorschot et al. 2010). NPD includes the identification and deployment of detailed characteristics that result progressively into genuinely new and improved products (Levitt 1985). The products are comprised of multiple traits and embedded components, such as quality, cost, technology, packaging and services, and any breakthrough in one dimension can be regarded as the production of new products (Takeuchi and Nonaka 1986). Seminal research work on NPD focuses on the innovative and strategic potential of the NPD cycle and the implications for the success or failure of the product launch (Schilling and Hill 1998; Veryzer 1998) and the key role of Big Data Analytics and AI have to play in this process (Trabucchi and Buganza 2019). 
Specific NPD details include changes in product structure, technical performance, or material that are superior to the previous generation, resulting in products more advanced and closer to consumer demand (Ding and Eliashberg 2003). When defining the functional requirements of a new product, critical factors need to be considered, such as technological progress, promoting business growth, increasing profits, increasing customer satisfaction, or reducing costs (Cooper et al. 2005). The company's new products can be original products, existing products with added unique characteristics, or new brands. At the same time, companies need to analyse the characteristics of new products, from different perspectives like sales, profits, customer groups, competitors and prices to make sure which product functions should be focused on in order to achieve success in the market.

For Hoyer et al. (2010), the NPD process includes four major stages: ideation, product development, commercialisation, and post-launch. In this study we focus on the first three, leaving the post-launch phase for further research, as it can be influenced differently from after-sales feedback (Ramanathan et al. 2017).

Ideation The idea screening stage is divided into a customer and a vendor source process (Barczak 1995). The customer-sourced idea screening process is well suited to the needs of a particular user or market and accounts for a large proportion of NPD (Hoyer et al. 2010). The manufacturer develops new products according to the original product ideas proposed by the customers. Product concept development is based on market demand through continuous communication and feedback information from the market (Barczak et al. 2009) thus an overall evaluation of the competitiveness and economic viability at each stage.

Product development Product development refers to developers' or engineers' research to design physical products based on product concepts, so that product ideas can be transformed into useful products (McCarthy et al. 2006). The product development process is transforming a product concept into a new product entity and mainly solving the problem of whether product ideas can be transformed into commercially and technically available products (Ferioli et al. 2010; Hoyer et al. 2010). The process is completed through the design, trial production, testing and certification of new products.

Commercialisation If the new product trial sales achieve the expected results, the company will decide to commercialise the new products (Barczak et al. 2009). At this point, the company should focus on the following aspects: choose the correct time to market, specific target market and right marketing mix strategy. To truly enter the commercial circulation and complete the final commercial realisation, the product also needs to go through a complete commercial packaging process to form a commodity. This usually includes activities such as customer delivery content, product sales policies, product sales brochures, product sales quotes, product sales agreements, and product after-sales services (Durmuşoğlu and Barczak 2011).

\subsection{Customer participation in NPD}

As the customers can have an iterative role in knowledge and opinion calls such as customer preferences, market demand and popular trends (Chong et al. 2016), customer involvement is deemed necessary for the NPD process (Lagrosen 2005; Tsinopoulos and Mena 2015). In order to ensure the smooth progress of the innovation process for the increasing need for more diversified and customised products, enterprises gradually realise the importance of user participation. User engagement can motivate companies to generate new ideas and encourage companies to invest more resources and capabilities into product innovation and 
process improvement (Poetz and Schreier 2012) supporting also customer value co-creation initiatives (Romero and Molina 2011).

Customer participation involves a relationship of sharing of resources between the customer and the enterprise in the process of enterprise NPD, providing valuable knowledge and information to the process (Chang and Taylor 2015). It has multiple manifestations such as: jointly developing new products or technologies; paying close attention to user demand for product performance, preferences on appearance types; implementing user knowledge management and better service NPD (Lin and Germain 2004). Customer engagement also could refer to the resources (capabilities, ideas, knowledge, investments) that users provide in NPD activities (Mikkola and Skjøtt-Larsen 2004).

The above definitions mainly describe the specific lines of user participation, defining the role of the user and the scope of activities involved. The involvement of customers in the NPD process is vast and could provide a competitive advantage for value co-creation (Hoyer et al. 2010), a decision-making mechanism (McCarthy et al. 2006) and a source of creativity (Stevens et al. 2003) for NPD. Combined with the above research, user participation our study is based on information resource sharing and performance improvement. The company actively invites users to participate in innovative activities such as product and technology process development, to achieve the absorption and utilisation of essential resources such as customer knowledge, information and capabilities.

\subsection{Al, social media and NPD}

Access to information about customers' product needs, preferences and needs are often seen as a foundation of successful innovation in NPD (Poetz and Schreier 2012; Chang and Taylor 2015; Lam et al. 2016; Hartmann et al. 2016). According to recent surveys, most enterprises regard social media information as an important source of enterprise's innovation (Cui et al. 2018; Chen et al. 2015), which is of considerable significance to enterprise product development. As a result, many researchers have focused on social media, applying social media data to their business processes, and integrating customers into the company's NPD (Du et al. 2016). Users can feedback product requests or ideas on social media platforms, and these online interactions or online comment exchanges have become the focus of NPD researchers (Chan et al. 2017; Fuchs and Schreier 2011; Gu and Ye 2014).

Artificial Intelligence (AI), as a principle, existed for over 6 decades, however, the last decade the term came back to popularity (Duan et al. 2019). Nowadays, AI is mostly applied for decision making; where the common role of AI is either to support/assist the human decision makers, or to replace them (Bawack et al. 2019; Duan et al. 2019; Dwivedi et al. 2019). One of the most popular AI techniques for decision-making is through text mining techniques, obtaining insight from social media content (Bawack et al. 2019; Fosso Wamba et al. 2019). As the progress of AI enables stakeholders to obtain knowledge from social media, new requirements evolve as to demystify the knowledge and make sense of it, and the major challenge is to undertake more complex tasks that require cognitive capabilities (Duan et al. 2019).

Many scholars have fully affirmed the critical value of social media for the process transformation but also product development (Aral et al. 2013). Social media can be a powerful platform for collaboration between companies and customers, where the user-generated content can provide valuable insights for operational development (Fader and Winer 2012). Piller and Walcher (2006) propose a social network-based creative contest application that allows manufacturers to get innovative ideas and solutions from their users. Social media also enable 
companies to monitor the list of competitors, track trends in other companies' news releases, identify new products, and understand potential customer needs (Fan and Gordon 2014).

The availability and use of social media have opened new ways of value creation and potential to business and process transformation ( $R a d$ et al. 2018), as well as unprecedented operational opportunities for collaboration (Kane et al. 2014). Moving beyond marketing value to innovative product development, multiple opportunities arise as social media provide new methods in marketing, information systems and social sciences research and can also go towards directions related to operations management, where the opportunities could increase for innovative processes, products or services (Leonardi 2014; Levina and Arriaga 2014).

Chae (2015) but also Mishra and Singh (2018) emphasize the potential role of social media for a wide array of supply chain practices (such as professional networks, stakeholder engagement, demand shaping, new product/service development and supply chain risk management). Singh et al. (2018) also posit that using text mining methods for social media analysis could help to improve the management of the supply chain. There is a growing body of literature that advocates that the analysis of data collected from social media, while focusing on the main concerns of consumers can provide a series of recommendations for developing a consumer-centric supply chain (Chae 2015; Lam et al. 2016; See-To and Ngai 2018; Singh et al. 2018).

\subsection{Sensemaking and social media}

Social media in general, and Twitter feeds in particular, are often used for expression of public opinion in the political discussion (Stieglitz and Dang-Xuan 2013), crisis management in emergencies (Fosso Wamba et al. 2019; Kumar et al. 2020; Singh et al. 2019) and information sharing for humanitarian operations (Maresh-Fuehrer and Smith 2016; Panagiotopoulos et al. 2016). Bruns and Stieglitz (2013) explain that often Twitter can support and influence various situations, spanning from isolated crises to cultural interactions, but also reviews of products and services (Rehman et al. 2016; See-To and Ngai 2018). However, the major problem identified in Twitter-based communication as a data collection method is the lack of standard metrics for comparing communicative patterns across cases (Bruns and Stieglitz 2013). Identifying and making sense of prevailing patterns within the collected data from social media, while disseminating and sharing information, could be challenging as various sources should be filtered and integrated for this process (Zeng et al. 2010). An additional challenge in the use of social media content could be around the different ways this content could be interpreted, or even misinterpreted (Stieglitz and Dang-Xuan 2013). Therefore, a rigorous analysis should be followed in order to extract the exact content specifics, and identify the various roles of the content generators, as well as their sentiment (Feldman 2013; Pang and Lee 2009).

Sensemaking is a generic term that refers to the processes of interpretation whereby individuals and groups interpret and reflect on phenomena (Weick et al. 2005). The sensemaking cycle iterates the social means of people enactment of their experiences and views, through verbal or written communication and negotiations (Light et al. 1967). In Operations and Supply Chain Management several best practices have been applied to enhance sensemaking, such as interaction with both suppliers and customers at trade shows, cross-organisational or cross-functional teams, or the use of the practice of the guest engineer at suppliers' sites. These practices facilitate the development of common understanding of critical issues. Through the development and use of a shared vocabulary, the individual understanding and 
Table 1 Research design

\begin{tabular}{|c|c|c|}
\hline Stage & Process and specifics & Contribution \\
\hline \multicolumn{3}{|l|}{ Research design } \\
\hline a. Data collection & $\begin{array}{l}\text { Process methods to collect the } \\
\text { twitter data (API development) } \\
\text { Specifics of the process defining the } \\
\text { product and the data collection } \\
\text { period }\end{array}$ & $\begin{array}{l}\text { Methodological (defining the data } \\
\text { collection requirements) }\end{array}$ \\
\hline b. Initial exploratory phase & $\begin{array}{l}\text { Process sentiment analysis of the } \\
\text { collected Twitter data } \\
\text { Specifics of the process identifying } \\
\text { the polarity and sentiment of the } \\
\text { customers' views for each of the } \\
\text { NPD phases }\end{array}$ & $\begin{array}{l}\text { Theoretical (enhancing sentiment } \\
\text { analysis background for NPD } \\
\text { process) } \\
\text { Methodological (defining sentiment } \\
\text { analysis requirements) }\end{array}$ \\
\hline c. In-depth analysis & $\begin{array}{l}\text { Process sensemaking approach } \\
\text { through fuzzy mathematics } \\
\text { Specifics of the process identifying } \\
\text { patterns in the data for each of the } \\
\text { NPD processes through techniques } \\
\text { of fuzzy mathematics }\end{array}$ & $\begin{array}{l}\text { Theoretical (sensemaking approach } \\
\text { for social media data analysis) } \\
\text { Methodological (defining } \\
\text { requirements for pattern analysis } \\
\text { through fuzzy mathematics) }\end{array}$ \\
\hline
\end{tabular}

appreciation is integrated to collective cognitions that shape decision making (Grant 1996; Revilla and Knoppen 2015).

Sensemaking as a way to define patterns from social media data can also be conceived as ethnomethodology to study different ways that people construct a stable social world through everyday utterances and actions (Garfinkel 2016). In our study, we apply an interpretative scheme and hermeneutics (Myers et al. 2011; Walsham 1995) to social media data, in order to elicit information and knowledge and identify the sensemaking patterns for the analysis of customer views. Therefore, the sensemaking approach as it is presented in this study provides a methodological grounding, where the application of fuzzy mathematics assists in identifying the patterns/themes in the data which can make sense for each of the NPD stages.

\section{Research design}

Our study is highly motivated and influenced by the work of Chan et al. (2016) that extracted data from Facebook via the NCapture tool. For accurate content analysis, the researchers selected the NPD-related factors (such as product price, product performance) by highfrequency word sorting to establish a model for NPD evaluation. Their model logically links the features that customers care most about with NPD. There are a few studies on NPD supporting how product performance can determine market strategy, product development process and product services (Cho and Lee 2013). Our study frames the whole analysis of the NPD process for the specific product in four distinct aspects related to the style-appearance, performance, configuration and service. These four features were identified as the common sensemaking patterns (prevailing themes in the data) characterised by the high frequency within the content of collected tweets (Mirbabaie and Zapatka 2017) and review the qualities of the product under research.

Our research design draws on three major stages (Table 1), namely: 
a. The data collection stage,

b. The initial exploratory phase (sentiment analysis)

c. The in-depth analysis (sensemaking approach through fuzzy mathematics).

The data collection process included the required methods to collect the twitter data, for a given product in a specific period. The exploratory phase served the purposes of an initial exploratory analysis of the collected Twitter data, identifying the polarity and sentiment of the customers' views for each of the NPD phases. The final stage adapted the principles of sensemaking in identifying patterns in the data for each of the NPD processes through techniques of fuzzy mathematics. These stages are explained further in the following subsections.

\section{First stage: data collection}

The case product As the automotive industry is one of the main research contexts in operations and supply chain management (e.g., Lin and Zhou 2011; Kim et al. 2011; Prahinski and Benton 2004; Wagner et al. 2009; Childerhouse et al. 2003), we selected as an exemplary case a product from the automotive industry as our research context. In recent years, with the exhaustion of energy and the popularity of new energy vehicles, people are increasingly aware of the importance of new energy vehicles and are beginning to buy new energy vehicles or electric vehicles. Tesla, an American electric vehicle and energy company, is the first to be sought. Moreover, Model X is a new model of Tesla and recently has entered the global market, therefore it could base as an example case the specifics of this study. Through the sentiment analysis and the fuzzy theory for text mining of tweets, we explore the variations of sentiments of the customers about the product. As quantitative methods of text analysis will also bring basis and support the results of the sentiment analysis, we postulate that we adopt a holistic perspective about the negative and positive emotions about Tesla's product development, or redesign stages.

Twitter data Our study is based on commentary twitter data about Tesla's Model X characteristics. Comments and responses to a tweet are also crucial as well as the retweeting behaviour (Bruns and Stieglitz 2013; Stieglitz and Dang-Xuan 2013). The Twitter open platform can easily provide developers with rich applications and complete service platforms using third-party access (Chae 2015). Developers can access rich interface resources according to the application service process, and there are plenty of data interfaces that can be collected, including tweets, users' information, content, relationships, and topics (Bruns and Stieglitz 2013; Mirbabaie and Zapatka 2017). There are two main types of data collection methods from Twitter: (1) Twitter Open Platform Application Programming Interface (API), which can conveniently and quickly obtain Tweets in batches and (2) Web crawler technology that can automatically extract information from web pages. Due to the freedom and freeness of the Twitter open platform, and for the purposes of this study, we chose to collect data through Twitter's free and open-source API, Tweepy, which is based on Python and can provide a large to a rich pool of data. In "Appendix A" we provide the code for the data collection and a snapshot of the collected data. 


\section{Second stage (exploratory phase)}

Twitter data and information are mostly in the form of text. Conducting a sentiment analysis with Tesla Model X's commentary can provide the means to consider the users' opinions. Our proposition is that by following the inclusion of social media in their NPD processes, Tesla could potentially match the needs of consumers as much as possible, and make rational decisions based on customer requirements.

The construction of a sentiment dictionary is a fundamental primary stage in the sentiment analysis. We used a lexicon-based approach to extract sentiment from the texts. The extent of which the sentiment dictionary could be comprehensive and accurate is primarily influenced by the results of the analysis of the emotional sentiment of the text (Burnap et al. 2015; McKenna et al. 2017). Our approach adopted the following process: We constructed a domain of emotional resources, developed the evaluation of information quaternions, and then calculated the emotional polarity of phrases and sentences (Lau et al. 2014).

A specific domain of sentiment lexicon has been constructed within a particular sentiment analysis environment. The expanded sentiment dictionary made up for the incompleteness of the basic sentiment dictionary, the disadvantages of domain emotional words and online emotional words are not included and improve the accuracy of emotional sentiment analysis. The construction of the domain sentiment dictionary comprised the selection of emotional seed words, the extension of the emotional dictionary (the field words are added to the dictionary), and the calculation of the weight of the emotional words.

\subsection{Research propositions}

Our research propositions were formed around five thematic clusters, related to product characteristics as these are introduced by Popescu and Etzioni (Popescu and Etzioni 2007):

Proposition 1 The customer is interested and comments on general characteristics of the product throughout the new product development lifecycle phases.

Proposition 2 The customer is interested and comments on the product's components throughout the new product development lifecycle phases.

Proposition 3 The customer is interested and comments on the appearance-aesthetics throughout the new product development lifecycle phases.

Proposition 4 The customer is interested and comments on the product's attributes throughout the new product development lifecycle phases.

Proposition 5 The customer is interested and comments on product-related concepts throughout the new product development lifecycle phases.

\subsection{Evaluation object and evaluation methods}

The five thematic clusters which formed the propositions of this research were applied as evaluation objects. The evaluation object of the tweet is the user's opinion on a specific aspect of a certain product. In the commentary information of the tweet, the evaluation object mainly refers to the product itself, a specific attribute or characteristic of the product, and the situation of some things related to the product itself (logistics, customer service, outer packaging). The 
five types of product evaluation objects used for the sentiment analysis could be summarised as (Popescu and Etzioni 2007): (1) the overall product, (2) the product's components, (3) the appearance-aesthetics, (4) the product's attributes and (5) product-related concepts.

The product evaluation objects (Popescu and Etzioni 2007) are represented in the tweets in the following exemplary manner.

1. "Tesla is very good" (the overall product) where the evaluation object is "Tesla" itself

2. "The design of the seat is not very suitable for human factors" (the product components) where the evaluation object is the part of the car "the seat of the car";

3. "The colour of this car is not good" (the appearance-aesthetics) where the evaluation object "colour" is related to the appearance of the car;

4. "The engine of Tesla's engine is not good" (the product's own attributes) where the evaluation object "engine" is the performance of the product;

5. "Regular maintenance is not good" (the product-related concepts) where "maintenance" is relevant to the product-related properties.

The extraction of the evaluation objects is mainly used to obtain the specific object for which the expression provides the evaluation information. In the study of the evaluation object extraction, the evaluation information corpus is pre-processed (discontinuation word processing, the lemmatisation and part-of-speech tagging), nouns or noun phrases are extracted as candidate evaluation object sets, and then the collection is performed by statistical methods. Finally, the noun words less than a certain threshold are removed, and the more frequent nouns or noun phrases are retained as the evaluation object set.

\subsection{Extraction of emotional words}

Our evaluation method followed a lexicon-based extraction method which is highly supported by Computational Linguistics research (Qiu et al. 2011; Taboada et al. 2011) in text mining unsupervised knowledge extraction through AI (Quan and Ren 2014; Rozenfeld and Feldman 2011). Firstly, the evaluation information was pre-processed, and then the processed words were compared with the pre-built emotional domain sentiment lexicon (adverb dictionary, negative words dictionary and turning words dictionary). If the word we found was in the dictionary, we concluded that this is an emotional word, and subsequently obtained the corresponding word information; if the word was not in the dictionary, then we evaluated the next words until the end of the whole sentence in the tweet. When emotional words were found in a sentence, the same method was used to traverse the negative dictionary, the adverb dictionary, the turning word dictionary. With this process, the corresponding word weight was obtained accordingly.

Based on the extraction of the evaluation words and the evaluation objects, a phrase-based quaternary model was then constructed. The evaluation path obtained the relevant elements of the phrase to facilitate the calculation based on the emotional polarity related rules of the evaluation information. For an evaluation message of Tesla on Twitter, the user evaluation information was segmented into phrases, and a four-tuple model of sentiment analysis was then constructed based on the phrase.

For example: "The engine performance is not good, but the GPS system is very good, and I like it very much." The evaluation information was divided into three phrases: "The engine performance is not good", "but the GIS system is very good" and "I like it very much". The evaluation factors were sequentially extracted for the evaluation phase. For the subjective evaluation information that did not contain commodity attributes such as "I like 
it very much", the pronoun "I" was directly removed during pre-processing, and only the emotional phrase "like very much" was retained.

\subsection{Calculation of emotional values}

For the sentiment analysis of tweets, the emotional tendencies of the constructed feature quads were analysed (Ilieva et al. 2018; Zhou et al. 2019). According to fuzzy statistical analysis, the common four-tuple of emotional phrases follow the four identified sets of conditions:

$$
\text { Evaluation Object }(\mathrm{O})+\text { Emotional Words (W) }
$$

In our analysis, the emotional extremes of the quad phrase were judged by combining the weight of the evaluation object and the emotional polarity and intensity of the words in the sentiment dictionary. For example, in the phrase "This car is beautiful", the commentary only contains the evaluation object "this car" and the evaluation of the emotional word "beautiful". When calculating the emotional polarity of the tweet, it is only necessary to multiply the weight of the evaluation object and the weight of the emotional word. In the tweets where the evaluation sentence contained a plurality of evaluation quads, all the quads were weighted and summed to obtain the emotional polarity of the entire sentence.

$$
\text { Evaluation Object }(\mathrm{O})+\text { Negative Words }(\mathrm{N})+\text { Emotional Words }(\mathrm{W})
$$

However, the emotional polarity of emotional words is not only related to negative words but also closely related to the number of negative words. When the quaternion performs the emotional polarity calculation, the weight of the evaluation object, the weight of the negative word, and the weight of the emotional word were multiplied to obtain the emotional extreme value of the emotional phrase. In the case where there were several negative words, the weight of the negative words was multiplied by the corresponding number of times. When the number of negative words was even, this was consistent with the polarity of the emotional words; in the case where the number was odd, this was opposite to the polarity of the emotional words. For example, for the tweets "this car is not beautiful," and "this car is not no beautiful", the number of negative words in these two sentences is different, and the apparent emotional polarity is inconsistent.

$$
\text { Evaluation Object }(\mathrm{O})+\text { Adverb }(\mathrm{Ad})+\text { Emotional Words }(\mathrm{W})
$$

An additional layer in our analysis included the tweets/sentences in which the appearance of modified adverbs could potentially enhance the emotional intensity of emotional words. The emotional polarity of a phrase changes appropriately with the degree of emotional adverbs based on emotional words. For example, in the tweet "this car is pretty beautiful", the inclusion of the degree adverb "pretty", the apparent emotional word "beautiful" is moderated. The calculation of the polarity of the emotional words is not a simple weighted summation, but on the basis of the extreme values of the modified emotional words, the emotional intensity is strengthened. The formula we used in our analysis is:

If the emotional word (W) is positive, then

$$
\text { Polarity }=(\mathrm{W})+(1-(\mathrm{W})) *(\mathrm{Ad})
$$

If the emotional word (W) is negative, then

$$
\text { Polarity }=(\mathrm{W})+(-1-(\mathrm{W})) *(\mathrm{Ad})
$$


Table 2 Examples of calculations of quaternions of emotional values

\begin{tabular}{lllr}
\hline Type of combination & Formula & Example & Value \\
\hline $\mathrm{S}=\mathrm{W}$ & $\mathrm{W}$ & This car is beautiful & 0.7 \\
$\mathrm{~S}=\mathrm{N}+\mathrm{W}$ & $\mathrm{N} * \mathrm{~W}$ & This car is not beautiful & -0.7 \\
$\mathrm{~S}=\mathrm{N} 1+\mathrm{N} 2+\mathrm{W}$ & $\mathrm{N} 1 * \mathrm{~N} 2 * \mathrm{~W}$ & This car is not no beautiful & 0.7 \\
$\mathrm{~S}=\mathrm{Ad}+\mathrm{W}$ & Positive: $\mathrm{W}+(1-\mathrm{W}) * \mathrm{Ad}$ & This car is pretty beautiful & 0.91 \\
& Negative: $\mathrm{W}+(-1-\mathrm{W}) * \mathrm{Ad}$ & This car is pretty ugly & -0.91 \\
$\mathrm{~S}=\mathrm{N}+\mathrm{Ad}+\mathrm{W}$ & Positive: $\mathrm{W} * \mathrm{~N}+(1-\mathrm{W}) * \mathrm{Ad}$ & This car is not pretty beautiful & -0.49 \\
& Negative: $\mathrm{W} * \mathrm{~N}+(-1-\mathrm{W}) * \mathrm{Ad}$ & This car is not pretty ugly & 0.49 \\
\hline
\end{tabular}

Taking the previous example into account, if the value of the emotional word "beautiful" is 0.7 , then the emotional phrase "pretty beautiful" is $(0.7+(1-0.7) * 0.7)$ is 0.91 . Based on obtaining the weight of the emotional words, the weights of the evaluation objects were subsequently weighted and summed to obtain the emotional extreme values of the evaluation phrases.

\section{Evaluation Object $(\mathrm{O})+$ Negative Words $(\mathrm{N})+$ Adverb $(\mathrm{Ad})+$ Emotional Words $(\mathrm{W})$}

In tweets where the negative words and adverbs appeared at the same time, based on the multiplication of the weights of the sentiment words and the weights of the negative words, the weights of the evaluation objects were weighted and summed to obtain the emotional extremes of the evaluation phrases. The formula we used in our analysis is:

If the emotional word (W) is positive, then

$$
\text { Polarity }=(\mathrm{W}) *(\mathrm{~N})+(1-(\mathrm{W})) *(\mathrm{Ad})
$$

If the emotional word (W) is negative, then

$$
\text { Polarity }=(\mathrm{W}) *(\mathrm{~N})+(-1-(\mathrm{W})) *(\mathrm{Ad})
$$

The above rules cover the emotional expression of most of the commentary phrases. Our analysis was built on the method proposed by Taboada et al. (2011), as a formula for calculating the emotional polarity of the quaternary (Table 2).

By using the degree adverbs, negative words, sentiment lexicons, and several statistical rules introduced above, the emotional polarity and emotional extremes of most evaluation information quads were calculated. In "Appendix B" we provide the code in python for the sentiment analysis.

\section{Third stage: in-depth analysis (sensemaking patterns based on fuzzy mathematics)}

In the previous section, we discussed in detail the way that the sentiment analysis was performed on Tesla's Model X for a single tweet message. For the sentiment analysis of a single tweet, the method directs to one of the five categories of the user's emotional tendency toward the product \{very good, good, average, poor, very poor $\}$. The proposed method can be convenient for the decision-makers or the company (Tesla) to categorize and understand the polarity of the information. However, it may take a lot of time to go through the five 
Table 3 Example of category for evaluating features

\begin{tabular}{lll}
\hline First-level indicator & Second-level indicator & Object \\
\hline B1 style appearance & C1 Colour & Black, white, silver-metallic, sky-blue \\
& C2 Space & Enough, crowded, small \\
C3 Shape & Flat, double-door \\
B2 Performance & C4 Speed & Fast, slow-start, acceleration \\
& C5 Engine & Powerful, dynamic \\
B3 Configuration & C6 Displacement & Low-emission \\
& C7 Sunroof & Airy, ventilate \\
C8 GPS & Accurate, sensitive \\
B4 Service & C9 Seat comfort & Comfortable, leathery \\
& C10 Price & Cheap, expensive \\
& C11 Maintenance & Complete, leather-protection \\
& C12 Cleanliness & Clean, dirty \\
\hline
\end{tabular}

categories to see the attitude of each tweet. For that purpose, the proposed method of a fuzzy comprehensive evaluation is used for sentiment analysis, to quantify the qualitative emotional tendency and to calculate the complete emotional value of the commodity through a detailed evaluation model. This comprehensive value can assist the company (Tesla) to decide, plan and improve the future steps or processes of NPD.

\subsection{Classification of evaluation objects}

The following step in our analysis of Twitter feeds was the construction of the evaluation indicator system of Tesla's X model. The evaluation indicator system was used to summarise and reflect the users' appreciation of the product (Zhou et al. 2019). Due to their generality, the evaluation indicators cannot cover all the evaluation objects. Hence, the evaluation objects were classified to obtain the fuzzy evaluation and the index weights by using fuzzy statistics so as to conduct a comprehensive sentiment analysis on Tesla (Vatrapu et al. 2016; Zhou et al. 2019). In order to obtain the aspects of Tesla's X model that consumers are interested in, first we conducted a word frequency statistic of all the words that were used in the twitter comments. Our analysis shows that the words "grey", "small", "V-shape", "fast", "powerful", "low-emission”, "big-sunroof”, "accurate”, "comfortable”, "economy”, "good service” and "clean" are the most frequently used about the X model. Based on these evaluation objectives, all the evaluation objects were classified according to the first-level indicators and the second-level indicators determined in the indicator structure model. The specific categories are shown in Table 3 below.

\subsection{Construction of indicator system}

The evaluation indicator system is a core and critical link in the evaluation of Tesla vehicles. In the indicator system for building a certain product, many scholars have constructed various reasonable structural models of commodity evaluation indicators, which can bring a lot of substantial help to the company's further development. Based on the analysis of many structural models (e.g. Soukhoroukova et al. 2012; Malviya and Kant 2016; Wu et al. 2015) 
Fig. 1 The evaluation indicator system

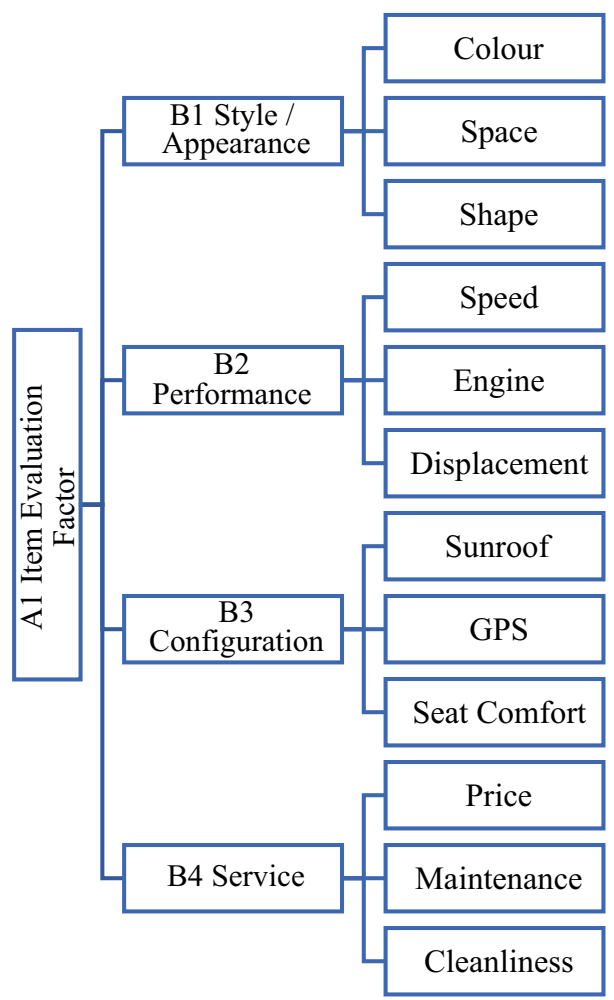

and combined with the evaluation information of users on Twitter, the indicator structure model for our study is shown in Fig. 1. For Tesla's evaluation indicator structure model, the determination of indicators is a factor that most users are concerned about. However, we acknowledge that there can be evaluation models that can include more or other indicators.

\subsection{Determination of the evaluation indicators}

In the process of fuzzy evaluation of products (Malviya and Kant 2016; Wu et al. 2015), each evaluation indicator has a different influence on the product, so it is necessary to calculate the weight coefficient of the indicator reasonably. At present, there are two standard methods for calculating the weights of the fuzzy comprehensive evaluation indicators: subjective and objective weighting methods. The first is based on the subjective judgment of an individual's comments to determine the index weight. There are some common subjective weighting methods, such as the Delphi method and the direct judgment method. The subjective weighting method is convenient and straightforward to use, but it strongly relies on people's judgements. The objective weighting method uses statistical methods, and the weights are determined according to statistical correlations, such as principal component analysis, entropy method, etc. This method has a more accurate theoretical basis, higher credibility, and is suitable for a large amount of data, but the calculation is relatively cumbersome.

The weight determination method that we used is more in line with objective facts than the method used by the previous researchers. It can not only use large-scale evaluation informa- 
tion, but also make the weight determination more convincing, and can carry out incremental weight calculation. At the same time, it reduces the tediousness of double counting, saves time, and maximises the use of tweet information.

Based on the advantages and disadvantages of the above two methods, we propose a more concise and easier to understand evaluation index weight assignment method.

- First, we count the number of pieces of comment information of the item (n)

- Then, we obtain the evaluation object through the extraction method of the evaluation object mentioned earlier

- Finally, the frequency of mention of each evaluation object is multiplied by the score of the previous sentiment analysis.

\subsection{Example analysis}

Based on the previous steps of the sentiment analysis, the secondary indicator score is equal to the average of the scores in the tweet containing corresponding objectives. Based on each secondary indicator, we can calculate a rating for each primary indicator. This is calculated by dividing the sum of all secondary indicator scores by the number of secondary indicators (Shown in Table 4).

An indicative example of the sentiment analysis is shown in Table 5. We provide only one example for illustration purposes, due to the large number of the collected tweets (also shown in "Appendix C").

Style/appearance Based on our analysis, the score of the style/appearance indicator is 0.31 ( 0.78 in colour, 0.02 in size and 0.14 in shape) and the proportion of style/appearance is 0.28 . As can be seen from the data in Table 4, the users are positively disposed toward the style/appearance of Tesla Model X. Style/appearance's mention rate is about $28 \%$ of the sum of the four aspects. Based on the data, this part focuses on how to conduct the NPD process from two aspects, namely idea generation and idea screening.

Performance The score for the performance indicator is -0.04 ( -0.36 in terms of speed, -0.23 in terms of engine, 0.46 in terms of displacement) and the proportion of performance is 0.33 . The performance of the Tesla Model X is the company's first priority. On the one hand, the performance rate of mention is the highest of the four first-level indicators. On the other hand, according to the user's tweets, the performance of Model X appears to be at a medium level. Based on this analysis, we can extrapolate that Tesla's design department should pay attention to this aspect of the products' characteristics.

Configuration The score for the configuration indicator is $0.32(-0.24$ for the sunroof, 0.85 for the GPS and 0.35 in terms of seat comfort). $18 \%$ of users' comments focus on the product's configuration and the proportion of the configuration indicator is 0.18 . According to our results, Tesla Model X's perceived evaluation in terms of configuration is considered good. The most frequent user tweets referred to the design of the sunroof. Based on our data, the configuration of the sunroof does not appear to meet consumers' expectations. Therefore, in the idea generation or the idea screening processes, the company should pay more attention to the redesign of the sunroof.

Service: The score of the service indicator is -0.33 ( -0.54 in price, -0.11 in maintenance and -0.34 in cleanliness) and the proportion of service is 0.21 . According to our results, Tesla Model X's overall service is in a poor state, especially in terms of price. For those users who tweeted about the product's service dimensions, price is also the most eminent issue. So, this part will focus on the price of the Tesla Model X. 


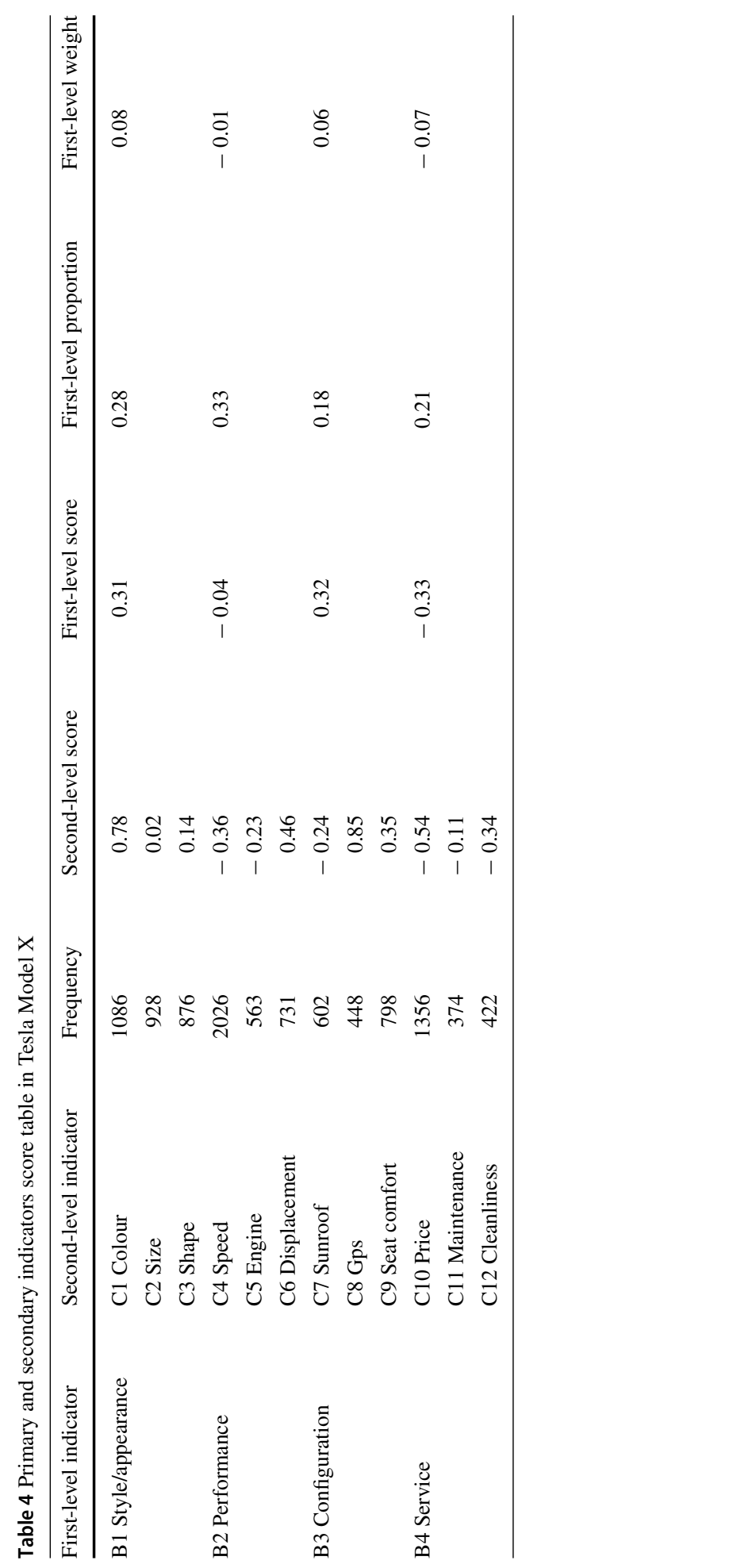


Table 5 Partial tweet analysis results

\begin{tabular}{|c|c|c|c|}
\hline Tweet & Objective & Second-level indicator & Score \\
\hline $\begin{array}{l}\text { My Tesla model X is only a low-profile version of } 70 \\
\mathrm{kWh} \text { (the } 85-\mathrm{kWh} \text { model is equipped with a } \\
\text { higher-powered motor), and the acceleration capability } \\
\text { is already mad, and I always want to test drive the P85D }\end{array}$ & Acceleration & Speed & -0.8 \\
\hline Tesla Model X's dynamic performance is amazing & Dynamic & Engine & 0.75 \\
\hline $\begin{array}{l}\text { Tesla's model } \mathrm{X} \text { during driving, my son said the seat } \\
\text { made him very comfortable }\end{array}$ & Seat & Seat comfort & 0.91 \\
\hline $\begin{array}{l}\text { rt omicrono tesla prepara un kart elctrico con forma de } \\
\text { model x para adultos }\end{array}$ & I & I & I \\
\hline $\begin{array}{l}\text { The new slipstream wheels offer a multi-axis design } \\
\text { similar to the previous cyclone, echoing the } \\
\text { streamlined lines of the Tesla Model X, which is great }\end{array}$ & Streamline & Shape & 0.7 \\
\hline
\end{tabular}

\section{Discussion}

\subsection{Implications for research}

In this paper, we set off to investigate how information retrieved from social media can assist decision-making processes and customer co-creation for NPD. Our analysis identified sensemaking patterns in Twitter data, thereby explaining the NPD process and the associated steps where the social interactions from customers can have an iterative role. We contribute to the literature of NPD using digital innovations (e.g. Akter et al. 2020; Fosso Wamba et al. 2019), as we discuss the importance of digital innovations (supported by technology-Twitter) in making people's emotions evident and present, and how people appreciate (or disapprove) the design of a product. Furthermore, we acknowledge the role of Big Data Analytics and AI in this process (Trabucchi and Buganza 2019) as we attempt to make sense of the use of Twitter data during NPD. Hence, we extend current studies (e.g. Kumar et al. 2020) in that we use this data to make sense of the proposed products during the NPD process, reinvigorating the role of customers as active participants in the process of co-creation (Irani et al. 2017). Therefore, we contribute to the research on effective customer involvement to create synergies and networks that are necessary for the creation of products that satisfy customer needs and aspirations and the strategic goals of the organisation (Romero and Molina 2011; Niesten and Stefan 2019).

By analysing Twitter data, we illustrate the usefulness of social media in the co-creation process as a sense-making device that assists managers and developers to make sense of the data available (Lycett 2013; Wei et al. 2014) and customer sentiment and decision-making opportunities (Duan et al. 2019; Dwivedi et al. 2019) throughout the whole NPD process (Zhan et al. 2018; Du et al. 2016; Fuchs and Schreier 2011; Majumdar and Bose 2019). Therefore, we argue that the NPD is inseparable from the familiarity with the law of market operation and the understanding of customer needs. It is necessary to first form market data and information into new product (technology) concepts, and then combine concepts into research and development projects. Social media is the optimal platform where the company can conduct data/sentiment collection and analysis which is a fundamental prerequisite for NPD. 


\subsection{Implications for practice}

This study has significant implications for practitioners and managers who are involved in NPD. It illustrates how companies can harness social media to improve aspects of the design. For instance, the results of the analysis of the case show that even though customers are satisfied in terms of the style/appearance of the studied product, $28 \%$ of the customers are concerned about the current style/appearance of the product. During the idea generation stage of product design, the company could consider what aspects of Model X's performance can be improved. The sentiment analysis can assist in the design of a brand new sunroof, but also help the company to improve the existing sunroof. In this way, social media data can help a company get ideas from consumers, but also to collect feedback related to opinion generation. For the screening phase, the results suggest that social media can play an important role in the idea screening stage. Big data analysis based on social media can perform behaviour analysis on users. In this way, companies can establish evaluation criteria in the idea screening process in NPD. Within the product development phase, a company could understand the target market conditions and define target consumers at the early stage of the new product market strategy formulation. Consumers are constantly changing their communication methods and consumption patterns in the face of different new media and platforms. Social media analytics provides real-time data to understand consumers' social media usage habits, social content, and the motivation behind them. Finally, in terms of commercialization, product managers (e.g. the product manager of Tesla Model X) need to consider these aspects, price, maintenance and cleanliness. On one hand, when faced with the advertising-based commercial product, the manager can emphasize this part of the repricing, as well as highlight free maintenance and cleaning services. On the other hand, product managers can develop value-added services, such as high-end paid maintenance, which can improve customers' satisfaction.

Our study calculates a score from the sentiment analysis, which is very useful for product managers, as it determines the customer satisfaction of aspects of Tesla Model X. The proportional which results from the fuzzy theory is used to determine which aspects of the product are the main objects mentioned by the user on Twitter. To be important, the weight, the product between the score and the proportion, determines the priority of each part of Tesla Model X in terms of existing and limited human resources, financial resources, and technical resources.

To sum up, our study highlights that social media can positively contribute to all the stages of NPD of a company. Social media can play three distinctive roles in a company's NPD process. Firstly, social media can help to explore the direction of innovation in new products. In addition to well-known platforms, many unfamiliar platforms, such as professional forums or blogs, also provide a wealth of information to help companies' NPD. Social media can also change the traditional way of exploring new ideas. NPD is often influenced by unanticipated market segments. However, traditional marketing research is difficult to reach these segments. Relying on social media makes it easy to get relevant information. A company simply needs to develop processes and systems that enable social media users to participate throughout the process. In addition, social media can assist in the commercialization of new product launches. A company can use social networking sites to achieve broad user engagement and generate innovative and interactive ways to spark customer interest in new products.

\section{Conclusion}

An important application area of Data Analytics and AI is to mine and analyse a large number of product reviews on social media. Its primary purpose is to discover underlying patterns 
to assess more accurately certain capabilities and drawbacks of products or services (Chan et al. 2016; Fader and Winer 2012). The utmost interest of a product review is to support a company through $\mathrm{AI}$ in identifying and obtaining the characteristics or attributes of the product, know the subjective comments of the user, extract comments and collocations, and distinguish the user's tendency (Singh et al. 2017) so that the company can plan and tailor the production strategy analogously. The extraction of information serves many roles for NPD, like market research, collections of customer's requests and the choice of strategy. The information extracting and sensemaking of product reviews is mostly based on data mining techniques of AI. However, since the subject of the product review is the name of the product, the focus of the product review is to extract information around the specific characteristics of the product and the corresponding emotional words (Bruns and Stieglitz 2013).

With the popularity of Internet users, social media have become an important part of people's daily lives. The sentiment analysis and fuzzy analysis of the evaluation of products in social media can affect the process of NPD to a certain extent. Based on our study's objectives, we carried out an in-depth research and generated insights for the improvement of the use of social media in the NPD process through a combination of sentiment analysis and fuzzy mathematics for the identification of sensemaking patterns that can assist companies in several stages of NPD.

The limitations of the study have to do with the limited generalisability because of the choice of one case in a particular context. However, the aim of the study is not about statistical generalizability (Guba and Lincoln 1994; Lincoln and Guba 1990); rather, it is about theory generalization from the case findings (Yin 2009), where theory is informed of a phenomenon and results are judged based on the appropriate reasoning used when discussing the findings and conclusions.

A potential extension of our study could be to examine other operations decision-making areas, such as sales forecasting and supply chain risk assessment. It would be interesting also to focus on various stages of product development such as concept development, business analysis, and prototyping. The sentiment analysis method that we propose subdivides the emotional vocabulary to a certain extent and obtains five evaluation grades, which have achieved certain effects. However, several limitations allow further refinement of emotion and the understanding of the emotional semantic level. Exploring new methods of identification through AI of the emotional polarity and more dimensions could extend the research scope of this study for the future. To improve the reliability of fuzzy evaluation analysis, it is necessary to increase the research on the degree of discrimination of indicators. The evaluation information sentiment analysis classification results have a low recall rate and an unstable accuracy rate. In the future research, different data are selected for comparative experiments, and the reasons for the instability of the evaluation results are found, and the classification accuracy and recall rate of each level are further improved.

Open Access This article is licensed under a Creative Commons Attribution 4.0 International License, which permits use, sharing, adaptation, distribution and reproduction in any medium or format, as long as you give appropriate credit to the original author(s) and the source, provide a link to the Creative Commons licence, and indicate if changes were made. The images or other third party material in this article are included in the article's Creative Commons licence, unless indicated otherwise in a credit line to the material. If material is not included in the article's Creative Commons licence and your intended use is not permitted by statutory regulation or exceeds the permitted use, you will need to obtain permission directly from the copyright holder. To view a copy of this licence, visit http://creativecommons.org/licenses/by/4.0/. 


\title{
Appendix A: Python codes for collecting twitter data
}

\author{
1 import [weepy \\ 2 import json
}

3

4 consumer key = "89ODEOSHOLz7yMqoYVbc54f8X"

5 consumer secret $=$ "nR0906C8qcz57YAu8CIG9Yjvj1Si8ge1J6nCWrq3J5zwajGCJT"

6 access token $=" 1017871918995787781-$ gMfna2Obw3bMXyfiQ6COvvNnJYpdOz"

7 access_token_secret = "vivzEpAfesIy5tp0vW8A37402zHWvpusS7Q0kmsE6TEgu"

8

9 auth $=$ tweepy.0AuthHandler(consumer_key, consumer secret)

10 auth.set_access_token(access_token, access_token_secret)

11 api $=$ tweepy.API(auth)

12 output_file=open ('data/Tw.txts, 'a', encodingwutf-8')

13

14 search_results $=$ api.search $\left(q\right.$ wtesla $\left.\operatorname{model} \mathrm{z}_{\mathrm{e}}^{\prime} \operatorname{count}=20000\right)$

$15 \quad i(q=$ key words, count $=$ the amount of data $)$

16

17

$18 *$ Iterative operation

19 for tweet in search_results:

20 if 'text' in tweet. json:

21 print('Tweet:'+tweet.text,filesoutput_file)

22 'Converting to a string and save it to a file

23 output_file.close() 


\section{Appendix B: Python codes for sentiment analysis}

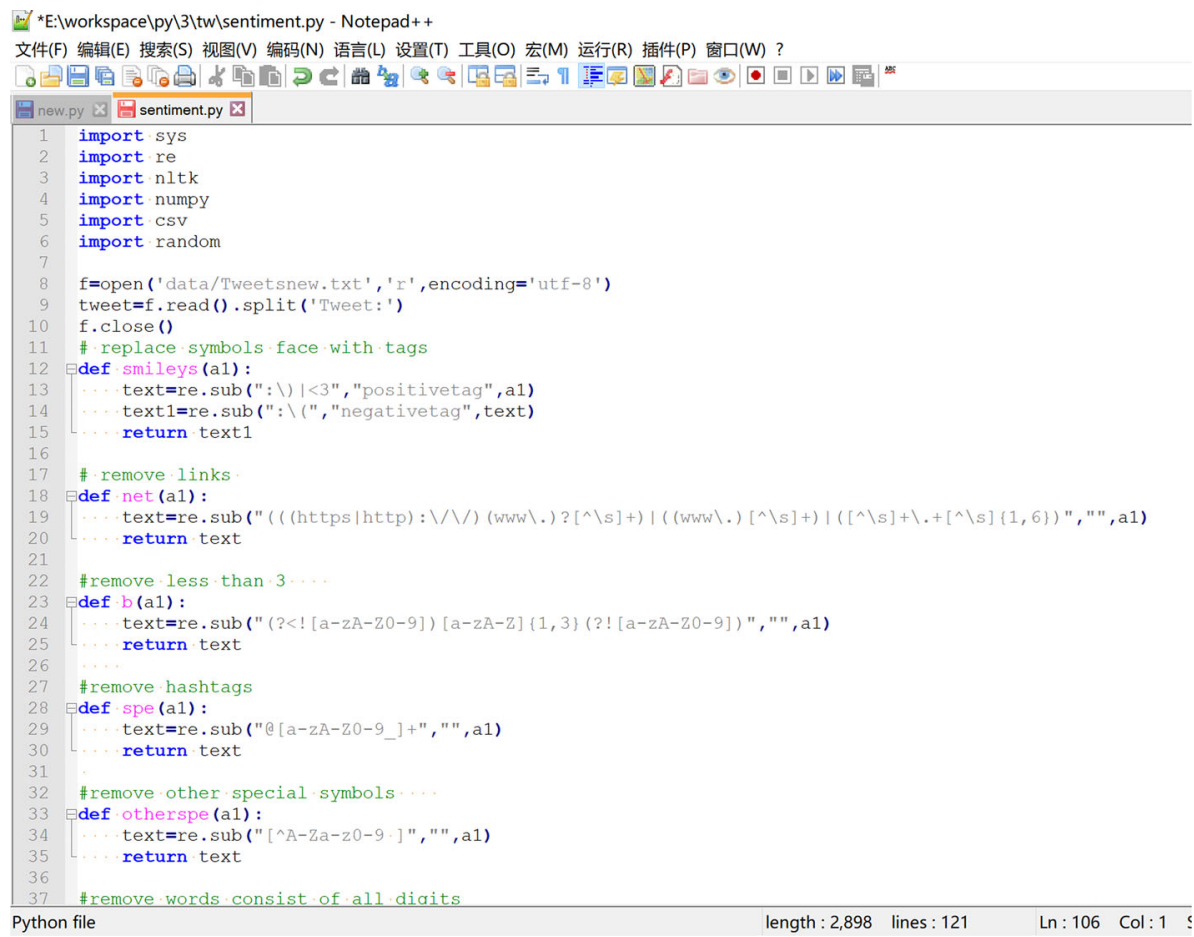




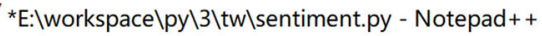

文件 $(F)$ 编辑 $(E)$ 搜索 $(S)$ 视图 $(V)$ 编码 $(N)$ 语言 $(L)$ 设置 $(T)$ 工具 $(O)$ 宏 $(M)$ 运行 $(R)$ 插件 $(P)$ 窗口(W) ?

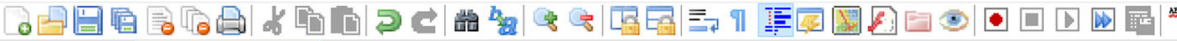

new.py $\mathrm{X}$ sentiment.py $\mathbf{X}$

\#remove words consist of all digits

def puredig (a1) :

text=re.sub $("(?<![a-z A-z 0-9])[0-9]+(? ![a-z A-z 0-9]) ", " n, a 1)$

return text

\#remove stopwords

$\exists$ def stopw (a1):

stopwords $=$ nltk. corpus. stopwords.words ('english')

text $=[\mathrm{w}$ for $\mathrm{w}$ in $\mathrm{a} 1$ if $n o t \cdot \mathrm{w}$ in stopwords $]$

return text

\#change word format by lemmatizer

Đdef wordbase (a1) :

lemma=nltk. WordNetLemmatizer ()

for $i$ in range (len (a1)):

a1 [i]=lemma. lemmatize (a1[i])

return a1

for $i$ in range (len (tweet)):

tweet [i] $=($ otherspe $($ tweet [i]) ). lower ()

\#

for $i$ in range (len (tweet)) :

tweet $[i]=(\operatorname{puredig}($ otherspe $(\operatorname{smileys}(\operatorname{spe}(\operatorname{net}(\operatorname{tweet}[i]))))))$. lower ()

wordlist $=[]$

for $i$ in tweet:

wordlist.append (re.split $\left({ }^{\prime}++"\right.$, i.strip(" .")))

\#save opinion lexcion into list

allword $=[$ ]

for $i$ in wordlist:

allword $+=i$

stopwords $=$ nltk. corpus.stopwords. words ('english')

filtered wordsall $=[\mathrm{w}$ for $\mathrm{w}$ in allword if not $\mathrm{w}$ in stopwords 1 
*E: workspace $\backslash p y \backslash 3 \backslash t w \backslash$ sentiment.py - Notepad++

文件 $(\mathrm{F})$ 编辑 $(\mathrm{E})$ 搜索 $(\mathrm{S})$ 视图 $(\mathrm{V})$ 编码 $(\mathrm{N})$ 语言 $(\mathrm{L})$ 设置 $(\mathrm{T})$ 工具 $(\mathrm{O})$ 宏 $(\mathrm{M})$ 运行 $(\mathrm{R})$ 插件 $(\mathrm{P})$ 窗口 $(\mathrm{W})$ ?

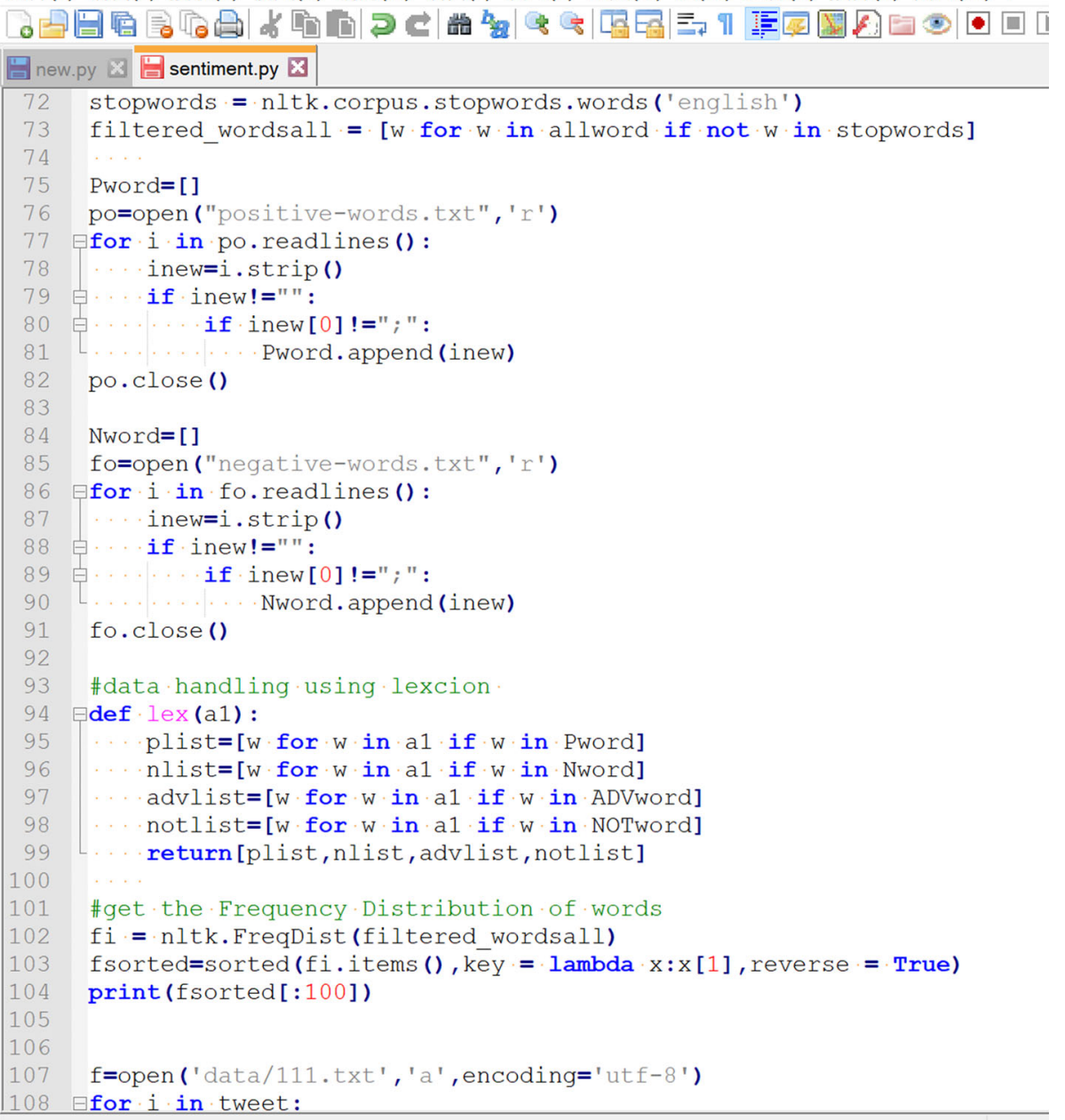


*E:\workspace \py\3\tw\sentiment.py - Notepad++

文件 $(F)$ 编辑 $(E)$ 搜索 $(S)$ 视图 $(V)$ 编码 $(N)$ 语言 $(L)$ 设置 $(T)$ 工具 $(O)$ 宏 $(M)$ 运行 $(R)$ 插件 $(P)$ 窗口 $(W)$ ?

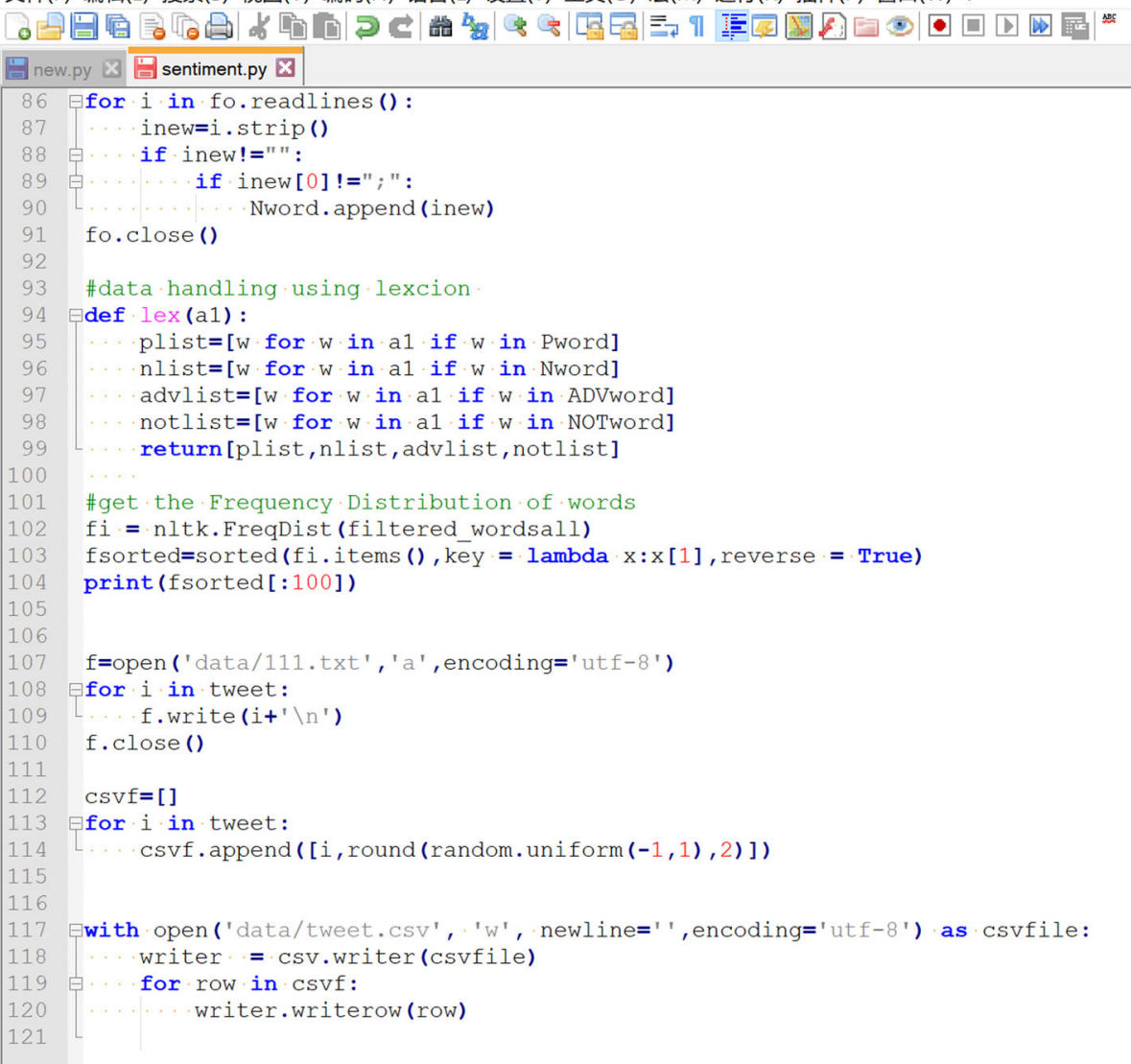




\title{
Appendix C: Partial raw data from 2000 tweets
}

\author{
17. Tweetsnew - Notepad \\ File Edit Format View Help \\ Tweet:RT QItsforexTime: Did you ever want to drive a Tesla? Join FXTM's "Wheel of Fortune" raffle contest from Jul-oct 2018 and you'll have a cha. \\ TWeet:RT ED_Love: If I refer 5 people with this link I can give my 3 year old nephew a mini-Tesla. Please RT!eYou can use my Tesla referral lin... \\ Tweet:RT QGenius: @officialjaden was one of the first to cop the tesla model $x$, so it makes sense that he's got elon musk on speed dial whttps:- \\ Tweet:@Phil_RX @Elrieur3 Ecoute je te laisse à ton job alors, moi je vais attendre la livraison de la mienne! Entre nous... https://t.co/rWdrP2SuzO \\ TWeet:Tesla model $x$ 見てきた。
}

スーパーからら功すた。

全面汃次粦

パラシリクウインドシール

は去んと䍐動た。

雨の昰䣋芯い,

TWeet:RT @ereigggne: I love when people think getting a minimum wage job can get your mom a new house, a McLaren, a Tesla model x, 3 gucci bags, a. Tweet:RT QFredericlambert: An all-electric solar-powered car drives by an abandoned Shell gas station next to a @iesla Model $x$. Glimpse at the fu TWeet:RT Q Tweet:RT eperstesla: @Tesla @elonmusk The Tesla Model X's key FOB is kept in the ' $X$ Box', which is fancy cube given to each new Tesla owner. WhyTweet:Elon Musk: "probably my personal favorite for the next product is the pickup truck, and we are going to just do an... https://t.co/b55Y2olTLh Tweet:@BolsacomTrading Tesla gana $25.000 \$$ netos con cada Model $S$ o $X$ que vende. Pero luego invierte mucho en la red Super... https://t.co/wdzPnKeBPo Tweet:Mне понравилось видео "Tesla Model X: обзор владельца" (https://t.co/RRi1yPH3Np) на @YouTube.

Tweet:\#Tesla quite disappointed of your support. Already waiting 2 months for getting an software update for our Model $X_{2}, \ldots$ https://t.co/yupwez5n8B Tweet:Get free supercharging if you order a new Tesla Nodel $X, S$ or $P 3$ https://t. co/lssiBWNPfO

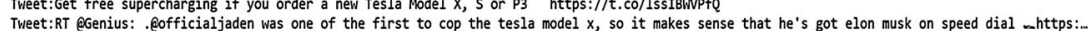
Tweet:RT GGenius: .eofficialjaden was one of the first to cop the tesla model $X$, so it makes sense that he's got elon musk on speed dial antps
Tweet:\#Tesla Should refresh the model $S$ and/or $X$ at 2020 otherwise, it could be too late because of the competitor to the luxury EV Market.

Tweet:Interested in purchasing a Tesla Model $S, X$ or 3 Performance and want free unlimited supercharging? If you know an... https://t. co/DGkUEYekIj

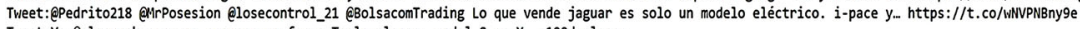
Tweet: Yo Qelonmusk can you sponser me for a Tesla please, model $\mathrm{S}$ or $\mathrm{X}$, p10ed please

Tweet:This customer I served asked for some help to take her shit to her car and I was like yeah calm gucci, I walk out a... https://t.co/mGz3Gupk8S Tweet:Thinking about buying a Tesla Model S, Model X, or Model 3 Performance? Use this link by September 16 to get free u... https://t.co/eMxHFacGFt Tweet:@elonmusk would people who ordered Model $X$ and $S$ with premium package be eligible fo get a price reduction now it's... https://t.co/217hSMLgJS Tweet: @oetroitBoRg $U$ should get a tesla Model $x$

Tweet:Tesla has model $S$ and model $X$. Aren't they missing model E?...... and if they have model $F$, they can run a 3-F-S-E-... https://t.co/Z0QpzDHRVy Tweet:If anybody wants free êTesla Super Charging and plans to complete order (any Model S / Model X or Performance Model... https://t.co/4gVkiaooRp Tweet:Und weiter gehts: Tesla Model $X$ zu verkaufen - Eine weitere spannende Empfehlung https://t.co/D1k48weedK https://t.co/srei6pJot 3

Tweet:RT @ItsforexTime: Did you ever want to drive a Tesla? Join FXTM's "Wheel of fortune" raffle contest from Jul-oct 2018 and you'll have a cha... Tweet:RT @itsforexTime: Did you ever want to drive a Tesla? Join FXTM's "Wheel of forth
Tweet:RT @iTeslaMotrsports: The Tesla Model $x$ dance\&\&\&\&777 https://t.co/1vlvzihJtl

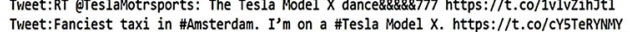

Tweet:Fanciest taxi in \#Amsterdam. I'm on a \#Tesla Model X. https://t.co/cY5TeRYNWV
Tweet:Which is the best electric car in 2018? Audi e-tron vs Jaguar I-Pace vs Porsche Taycan vs Tesla Model X.. https://t.co/4RfVsn7wW

TWeet:RT @Fredericlambert: An all-electric solar-powered car drives by an abandoned Shell gas station next to a @Tesla Model X. Glimpse at the fu. Tweet:Nowadays software/media companies are using subscription model to pay for service. Hey @iesla [elonnusk here is a b... https://t.co/6hcwwKPhI7 Tweet:Hi everyone I I want to share something new and interesting! U must joinaABCC_Exchange AT competitionTesla Mode... is very butifully https://t.co/kJeyj8mc1r Tweet:Check out my referral link which gives you free Supercharging on Model S, Model $X$, or Model 3 Performance, or a 5-y... https://t.co/kowl08VDzB9 Tweet:RT QHMbyrepower: Fabrizio Giugiaro: "L'incredibile possibilità di espressione dettata dalla \#autoelettrica deve andare a vantaggio dell'ori. Tweet:RT Qreigggne: I love when people think getting a minimum wage job can get your mom a new house, a McLaren, a Tesla model $x, 3$ gucci bags, a Tweet:RT AFredericlarbert: An all-electric solar-powered car drives by an abandoned Shell cas station next to a OTesla Nodel $x$, Glimpse at the fu Twet:Rr efr Tweet:RT eteslectring Tweet:RT eperstesla: eresla eelons Tweet:Elon Musk: Tweet:@BolsacomTrading Tesla gana 25.000\$ netos con cada Model $S$ o $X$ que vende. Pero luego invierte mucho en la red Super... https://t.co/wdzPnKeBPo Tweet:Мне понравилось видео "Tesla Model X: обзор владельца" (https://t.co/RRi1yPH3Np) на @QYouTube.

TWeet:RT QClimatecouncil: \#EV competition is shaping up \&yundai Kona $\vee$ Tesla Model $\mathrm{X}$ battle for long distance travel title o https://t.co/pfIyw.. Tweet:I think having "overtrust" \#Oriverlesscars is more dangerous than the lack of trustl Automation \# Autonomy ... read... https://t.co/rg8b7fh2R7 Tweet:Tesla's model $x$ during acceleration - so fast! •..teslamotors..*\#NAWSupercars \#tesla \#teslamofelx... https://t. co/66B8MIn77E

Tweet:RT @Omicrono: Tesla prepara un kart eléctrico con forma de Model $X$ para adultos https://t.co/f75wPodsIq https://t.co/hFhQPwqdzn

Tweet:Living with \#ElectricVehicles https://t.co/RKXnOdkjYb via eccleantechnica https://t.co/hXSOHT6THO

Tweet:RT Q Q未来可见: The Tesla Model X 非常的不耤, 哈哈, 我家入很喜欢

Tweet:RT Qevdigest: Tesla Model 3 inspired interior design coming to the Tesla Model $S$ and Model $X$ \#EV \#ElectricVehicles \#Tesla \#NodelS \#Nodel3.

Tweet:If you are going to buy a Tesla Model S, Model X, or Model 3 Performance, you can use a referral code to get unlimi... https://t.co/6PHK3aodf7 Tweet:Tesla Model 3 inspired interior design coming to the Tesla Model $S$ and Model $X$ \#EV \#ElectricVehicles \#Tesla... https://t.co/Xdffy57evd

Tweet: You can use my Tesla referral link for free Supercharging on Model $S$, Model $X$, or Model 3 Performance. You can also https: $/ /$ t. co/agkVuw6673 Tweet:You can use my Tesla referral link for free Supercharging on Model S, Model X, or Model 3 Performance. You can also... https://t.co/q9KVuw6673
Tweet:You can use my Tesla referral link for free Supercharging on Model S, Model $X$ or Model 3 Performance. You can also.. https://t.co/v24g7aR592 Tweet:You can use my Tesla referral link for free Supercharging on Model $\mathrm{S}$, Model $\mathrm{X}$ or
Tweet:Fotogaleria: Tesla Model $\mathrm{X}$ 100D - Espectáculo eléctrico https://t.co/XREfhYYMoy

Tweet:@efropoker @RealkidPoker I personally cant

stand the way the Tesla looks like a Mazda.. (\&amp; can't afford 120k model... https://t.co/wew4FacQFR

Tweet:yo Qelonmusk you trynna give me a free Tesla Model $x$

Tweet:Gebruik mijn referral-link voor gratis Supercharging voor Model $S$ of $\mathrm{X}$. https://t.co/HIn6PNjh6D

Tweet: $Y$ 'all start taking notes 2 cars $I$ 'm getting in 2 years a Tesla model $X$ and a hellcat remember $I$ said it

Tweet:RT QItsforexTime: Did you ever want to drive a Tesla? Join FXTM's "Wheel of Fortune" raffle contest from Jul-0ct 2018 and you'll have a chaTweet:Tesla Model $X$ 100D. Prize is so great. i like it https://t.co/5Fg3iSjRfU

Tweet:RT QItsForexTime: Did you ever want to drive a Tesla? Join FXTM's "Wheel of Fortune" raffle contest from Jul-oct 2018 and you' 11 have a cha. Tweet:Free UNLIMITED Tesla Supercharging ends Sep 16th | Model $S$, $x$, \&amp; Performance 3! Each code is linited to only 5 peop.. https://t.co/gofZTpxyhD Tweet:Free UNLIIS
Tweet: $i$ 'm not disappointed that $i$ didn't see anyone with a self-driving tesla model $x$ do the \#InMyFeelingschallenge as th... https://t.co/7bFr70uveK Tweet: 1 'n not disappointed that 1 didn't see anyone with a self-driving

Tweet:I liked a QYouTube video https://t.co/cepjIXQxhB Hot wheels Tesla Model $X$

Tweet:Tesla Model $x$ (als Superheld) | Julien Ban

Tweet:Model S, Model 3, Model X, Model Y. @Tesla is definitely building s3xy cars.

Twipet:RT Gmarkhsnieger: FRFSH DATA FROM SFCOND MFASIRF PROUTNG MDDFI 3 DFMAND TS A IDTSASTFR* 
3 Tweetsnew - Notepad

File Edit Format View Help

Tweet:Первый электрический Audi оказался круче Tesla Model x https://t.co/5FuJfikAKy

Tweet:Tesla's model $x$ during acceleration so fastlteslamotors\#MAbSupercars \#tesla \#teslamofel

Tweet:RT ROmicrono: Tesla prepara un kart eléctrico con forma de Model $\mathrm{X}$ para adultos https://t.co/f75wPOdsIq https://t.co/hFhoPwqdz

Tweet:Living with \#ElectricVehicles https://t.co/RKXnOdkjYb via (2cleantechnica https://t.co/hXSOHT6THE

Tweet:RT @evdigest: Tesla Model 3 inspired interior design coming to the Tesla Model $S$ and Model X \#EV \#ElectricVehicles \#Tesla \#Mode1S \#Model3...

Tweet:If you are going to buy a Tesla Model S, Model $x$, or Model 3 Performance, you can use a referral code to get unlimi... https://t.co/6PHK3aodf

Tweet:Tesla Model 3 inspired interior design coming to the Tesla Model $S$ and Model X \#EV \#Electricvehicles \#Tesla... https://t.co/Xdffy57evd

Tweet:You can use my Tesla referral link for free Supercharging on Model S, Model X, or Model 3 Performance. You can also... https://t.co/qeKVuw6673

Tweet:RT @Genius: @@officialjaden was one of the first to cop the tesla model $x$, so it makes sense that he's got elon musk on speed dial -https:.-

Tweet:You can use my Tesla referral link for free Supercharging on Model $S$, Model $X$ or

Tweet:Fotogaleria: Tesla Model X 1000 - Espectáculo eléctrico https://t. co/XREfhYYMoy

Tweet:yo @elonmusk you trynna give me a free Tesla Model $x$

Tweet:Gebruik mijn referral-link voor gratis Supercharging voor Model $s$ of $x$. https://t.co/HInGPNjh6D

Tweet: $Y^{\prime}$ all start taking notes 2 cars I'm getting in 2 years a Tesla model $x$ and a hellcat remember I said it

Tweet:RT @ItsForexTime: Did you ever want to drive a Tesla? Join FXTM's "Wheel of Fortune" raffle contest from Jul-oct 2018 and you'l1 have a cha..

Tweet:I added a video to a @YouTube playlist https://t.co/07peulGh65 modelXfamilie: Wir holen unser neues Tesla Model $X$ in Frankfurt ab

Tweet:RT @AbrahamJaro96: Tesla model $x$, bring yourself to me. ve

Tweet:@danarel Tesla sells more electric cars than any other manufacturer. It would be difficult to tackle both climate c... https://t.co/OBaYsB9mfu

Tweet:Yeah Tesla's share price needs to chill. I want to buy \$TSLA next year $\Theta$. Also I want to get a Model $X$ for my 30 th.

Tweet: Only in Silicon Valley you would get picked up by a Tesla Model $X$ while using the Lyft line $\theta$ holy shit this thing is dope

Tweet:Tesla Model $\times 1000$. Prize is so great. i like it https://t.co/5Fg3isjRfU

Tweet:RT @ItsforexTime: Did you ever want to drive a Tesla? Join FXTM's "Wheel of Fortune" raffle contest from Jul-oct 2018 and you' 11 have a cha..

Tweet:Free UNLIMITED Tesla Supercharging ends Sep 16th I Model S, X, \&amp; Performance 3! Each code is limited to only 5 peop... https://t.co/gofZTpxyh

Tweet:@Tesla @elonmusk @Jalopnik Where can I see or buy the MODEL $X$ ?

Tweet: I liked a QYouTube video https:1/t co/cepjixoxhB Hot wheels Tesla Model $X$

Tweet: Tesla Mode1 $x$ (als Superheld) i Julien Bam

Tweet:RT @teslectrics1: Elon Musk: "probably my personal favorite for the next product is the pickup truck, and we are going to just do an amazin..

Tweet:RT @TeslaMotrsports: The Tesla Model $X$ dance $\$$ https://t.co/1vlvZihJt1

Tweet:Model S, Model 3, Model X, Model Y. @Tesla is definitely building s3xy cars.

Tweet:RT @markbspiegel: FRESH DATA FROM SECOND MEASURE PROVING MODEL 3 DEMAND IS A *DISASTER*!

Tweet:I liked a @YouTube video https://t.co/53jQRdHaIE 2018 Tesla Model X Full-Self Driving TEST DRTVE - Amazing Autopilot System of Elon

Tweet:\#Tesla quite disappointed of your support. Already waiting 2 months for getting an software update for our Model $\mathrm{x}$,... https://t.co/yupwez5n8B

Tweet:Get free supercharging if you order a new Tesla Model $\mathrm{X}$, S or P3 https://t. co/1ssIBWVPfQ

Tweet:RT @Genius: . @officialjaden was one of the first to cop the tesla model $x$, so it makes sense that he's got elon musk on speed dial -

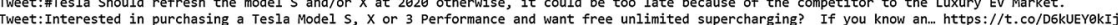

Tweet: Interested in purchasing a Tesla Model $s, x$ or 3 performance and want free unlimited supercharging? If you know an... https://t. Co/D6kUEYekI

Tweet: Yo (oelonmusk can you sponser me for a Tesla please, model $S$ or $X$,

Tweet: This customer I served asked for some help to take her shit to her car and I was like yeah calm gucci, I walk out a... https://t.co/mGz3GUpk8S

Tweet:Thinking about buying a Tesla Model S, Model $\mathrm{x}$, or Model 3 Performance? Use this link by September 16 to get free U... https://t.co/OMxHFacGFt Tweet: @elonmusk would people who ordered Model $X$ and $S$ with premium package be eligible fo get a price reduction now it's... https://t.co/217hSMLgJS Tweet:Pamela's Tesla referral link gives you free Supercharging on Model S, Model X, or Model 3 Performance, or a 5-year... https://t.co/89ABD3spRH Tweet:RT @ItsForexTime: Did you ever want to drive a Tesla? Join FXTM's "Wheel of Fortune" raffle contest from Jul-oct 2018 and you'll have a cha.. Tweet: @wcazz @Tesla Hey never say never. @elonmus

Tweet:@DetroitBORG $U$ should get a tesla Model $x$

Tweet: Tesla has model $S$ and model $X$. Aren't they missing model $E$ ? ....... and if they have model $F$, they can run a $3-F-S-E-\ldots$ https://t.co/ZoQpzDHRV Tweet:RT @_Tesla8: @elonmusk, I have driven the following Teslas: \#P108DL S 8amp; X, \#P3D, 3 LR, 100D X, 85D S, 60D S and I own a 2013 Model S 85! Bu Tweet:If anybody wants free @Tesla Super Charging and plans to complete order (any Model Tweet: Und weiter gehts: Tesla Model $x$ zu verkaufen - Eine weitere spannende Empfehlung https://t.co/D o

Tweet:RT @itsForexTime: Did you ever want to drive a Tesla? Join FXTM's "Wheel of Fortune" raffle contest from Jul-oct 2018 and you'll have a cha. Tweet: Fanciest taxi in \#Ansterdam. I'm on a \#Tesla Model $X$. https: $/ / \mathrm{t}$. CO/CYSTeRYNHY

Tweet:Which is the best electric car in 2018? Audi e-tron vs Jaguar I-Pace vs Porsche Taycan vs Tesla Model X... https://t.co/4RfVsn7wVz Tweet:RT @FredericLambert: An all-electric solar-powered car drives by an abandoned Shell gas station next to a @ịesla Model $X$. Glimpse at the fu. Tweet:Nowadays software/media companies are using subscription model to pay for service. Hey @Tesla @elonmusk here is a b... https://t.co/6hcwwkPhI

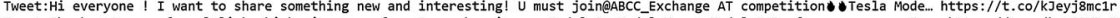
Tweet:Check out my referral link which gives you free Supercharging on Model $S$, Model $x$, or Model 3 Performance, or a 5-y... https://t.co/koweBvDzBg Tweet:RT @ Tweet:RT @ItsForexTime: Did you ever want to drive a Tesla? Join FXTM's "Wheel of Fortune" raffle contest from Jul-oct 2018 and you'll have a cha. Tweet:RT @D_Love: If I refer 5 people with this link I can give my 3 year old nephew a mini-Tesla. Please RT!@You can use my Tesla referral lin... wet:

\section{References}

Akter, S., Bandara, R., Hani, U., Wamba, S. F., Foropon, C., \& Papadopoulos, T. (2019). Analytics-based decision-making for service systems: A qualitative study and agenda for future research. International Journal of Information Management, 48, 85-95.

Akter, S., Michael, K., Uddin, M. R., McCarthy, G., \& Rahman, M. (2020). Transforming business using digital innovations: The application of AI, blockchain, cloud and data analytics. Annals of Operations Research. https://doi.org/10.1007/s10479-020-03620-w.

Aral, S., Dellarocas, C., \& Godes, D. (2013). Introduction to the special Issue-Social media and business transformation. Information Systems Research. https://doi.org/10.3233/IES-140532.

Bahemia, H., Squire, B., \& Cousins, P. (2017). A multi-dimensional approach for managing open innovation in NPD. International Journal of Operations and Production Management. https://doi.org/10.1108/IJOPM07-2015-0415.

Barczak, G. (1995). New product strategy, structure, process, and performance in the telecommunications industry. Journal of Product Innovation Management. https://doi.org/10.1111/1540-5885.1230224.

Barczak, G., Griffin, A., \& Kahn, K. B. (2009). Perspective: Trends and drivers of success in NPD practices: Results of the 2003 PDMA best practices study. Journal of Product Innovation Management. https://doi. org/10.1111/j.1540-5885.2009.00331.x.

Bawack, R. E., Wamba, S. F., \& Carillo, K. D. A. (2019). Artificial intelligence in practice: Implications for information systems research. In 25th Americas conference on information systems, AMCIS 2019.

Bruns, A., \& Stieglitz, S. (2013). Towards more systematic Twitter analysis: Metrics for tweeting activities. International Journal of Social Research Methodology. https://doi.org/10.1080/13645579.2012.756095. 
Burnap, P., Rana, O. F., Avis, N., Williams, M., Housley, W., Edwards, A., et al. (2015). Detecting tension in online communities with computational Twitter analysis. Technological Forecasting and Social Change. https://doi.org/10.1016/j.techfore.2013.04.013.

Chae, B. (2015). Insights from hashtag \#supplychain and Twitter analytics: Considering Twitter and Twitter data for supply chain practice and research. International Journal of Production Economics, 165, 247-259.

Chan, H. K., Lacka, E., Yee, R. W. Y., \& Lim, M. K. (2017). The role of social media data in operations and production management. International Journal of Production Research. https://doi.org/10.1080/002075 43.2015.1053998.

Chan, H. K., Wang, X., Lacka, E., \& Zhang, M. (2016). A mixed-method approach to extracting the value of social media data. Production and Operations Management. https://doi.org/10.1111/poms.12390.

Chang, W., \& Taylor, S. A. (2015). The effectiveness of customer participation in new product development: A meta-analysis. Journal of Marketing. https://doi.org/10.1509/jm.14.0057.

Chen, C., Zhang, J., Xie, Y., Xiang, Y., Zhou, W., Hassan, M. M., et al. (2015). A performance evaluation of machine learning-based streaming spam tweets detection. IEEE Transactions on Computational Social Systems, 2(3), 65-76.

Childerhouse, P., Hermiz, R., Mason-Jones, R., Popp, A., \& Towill, D. R. (2003). Information flow in automotive supply chains-Present industrial practice. Industrial Management and Data Systems, 103(3-4), $137-149$.

Cho, J., \& Lee, J. (2013). Development of a new technology product evaluation model for assessing commercialization opportunities using Delphi method and fuzzy AHP approach. Expert Systems with Applications. https://doi.org/10.1016/j.eswa.2013.03.038.

Chong, A. Y. L., Li, B., Ngai, E. W., Ch'ng, E., \& Lee, F. (2016). Predicting online product sales via online reviews, sentiments, and promotion strategies. International Journal of Operations \& Production Management, 36(4), 358-383.

Cooper, R., Jones, C., \& Perks, H. (2005). Characterising the role of design in a new product development: An empirically derived taxonomy. Journal of Product Innovation Management. https://doi.org/10.1111/ j.0737-6782.2005.00109.x.

Cui, R., Gallino, S., Moreno, A., \& Zhang, D. J. (2018). The operational value of social media information. Production and Operations Management. https://doi.org/10.1111/poms.12707.

Ding, M., \& Eliashberg, J. (2003). Structuring the new product development pipeline. Management Science. https://doi.org/10.1287/mnsc.48.3.343.7727.

Du, S., Yalcinkaya, G., \& Bstieler, L. (2016). Sustainability, social media driven open innovation, and new product development performance*. Journal of Product Innovation Management, 33, 55-71.

Duan, Y., Edwards, J. S., \& Dwivedi, Y. K. (2019). Artificial intelligence for decision making in the era of big data: Evolution, challenges and research agenda. International Journal of Information Management. https://doi.org/10.1016/j.ijinfomgt.2019.01.021.

Durmuşoğlu, S. S., \& Barczak, G. (2011). The use of information technology tools in new product development phases: Analysis of effects on new product innovativeness, quality, and market performance. Industrial Marketing Management. https://doi.org/10.1016/j.indmarman.2010.08.009.

Dwivedi, Y. K., Hughes, L., Ismagilova, E., Aarts, G., Coombs, C., Crick, T., et al. (2019). Artificial intelligence (AI): Multidisciplinary perspectives on emerging challenges, opportunities, and agenda for research, practice and policy. International Journal of Information Management. https://doi.org/10.1016/j.ijinfomgt.2 019.08.002.

Fader, P. S., \& Winer, R. S. (2012). Introduction to the special issue on the emergence and impact of usergenerated content. Marketing Science. https://doi.org/10.1287/mksc.1120.0715.

Fan, W., \& Gordon, M. D. (2014). The power of social media analytics. Communications of the ACM. https:// doi.org/10.1145/2602574.

Feki, M., Boughzala, I., \& Wamba, S. F. (2016). Big data analytics-enabled supply chain transformation: A literature review. In Proceedings of the 2016 49th Hawaii international conference on system sciences (HICSS), IEEE Computer Society (pp. 1123-1132).

Feldman, R. (2013). Techniques and applications for sentiment analysis. Communications of the ACM. https:// doi.org/10.1145/2436256.2436274.

Ferioli, M., Dekoninck, E., Culley, S., Roussel, B., \& Renaud, J. (2010). Understanding the rapid evaluation of innovative ideas in the early stages of design. International Journal of Product Development. https:// doi.org/10.1504/ijpd.2010.034313.

Fosso Wamba, S., \& Akter, S. (2019). Understanding supply chain analytics capabilities and agility for data rich environments. International Journal of Operations \& Production Management, 39, (6/7/8), 887-912. 
Fosso Wamba, S., Dubey, R., Gunasekaran, A., \& Akter, S. (2020). The performance effects of big data analytics and supply chain ambidexterity: The moderating effect of environmental dynamism. International Journal of Production Economics, 222, 107498.

Fosso Wamba, S., Edwards, A., \& Akter, S. (2019). Social media adoption and use for improved emergency services operations: The case of the NSW SES. Annals of Operations Research. https://doi.org/10.1007/ s10479-017-2545-9.

Fosso Wamba, S., Gunasekaran, A., Akter, S., Ren, S. J., Dubey, R., \& Childe, S. J. (2017). Big data analytics and firm performance: Effects of dynamic capabilities. Journal of Business Research, 70, 356-365.

Fosso Wamba, S., \& Queiroz, M. M. (2020). Blockchain in the operations and supply chain management: Benefits, challenges and future research opportunities. International Journal of Information Management, $52,102064$.

Fuchs, C., \& Schreier, M. (2011). Customer empowerment in new product development. Journal of Product Innovation Management. https://doi.org/10.1111/j.1540-5885.2010.00778.x.

Garfinkel, H. (2016). Studies in ethnomethodology. In Social theory re-wired: New connections to classical and contemporary perspectives: Second Edition. https://doi.org/10.4324/9781315775357.

George, G., Osinga, E. C., Lavie, D., \& Scott, B. A. (2016). Big data and data science methods for management research. Academy of Management Journal, 59(5), 1493-1507.

Grant, R. M. (1996). Toward a knowledge-based theory of the firm. Strategic Management Journal, 17(S2), $109-122$.

Gu, B., \& Ye, Q. (2014). First step in social media: Measuring the influence of online management responses on customer satisfaction. Production and Operations Management. https://doi.org/10.1111/poms.1204 3.

Guba, E. G., \& Lincoln, Y. S. (1994). Competing paradigms in qualitative research. Handbook of qualitative research, 2(163-194), 105. (Edited by: Denzin, N.K. and Lincoln, Y.S), 4th Edition, USA.

Hartmann, P. M., Zaki, M., Feldmann, N., \& Neely, A. (2016). Capturing value from big data-a taxonomy of data-driven business models used by start-up firms. International Journal of Operations \& Production Management, 36(10), 1382-1406.

Hoyer, W. D., Chandy, R., Dorotic, M., Krafft, M., \& Singh, S. S. (2010). Consumer cocreation in new product development. Journal of Service Research. https://doi.org/10.1177/1094670510375604.

Ilieva, G., Yankova, T., \& Klisarova-Belcheva, S. (2018). Decision analysis with classic and fuzzy EDAS modifications. Computational and Applied Mathematics. https://doi.org/10.1007/s40314-018-0652-0.

Irani, Z., Sharif, A. M., Papadopoulos, T., \& Love, P. E. (2017). Social media and Web 2.0 for knowledge sharing in product design. Production Planning \& Control, 28(13), 1047-1065.

Kache, F., \& Seuring, S. (2017). Challenges and opportunities of digital information at the intersection of Big Data Analytics and supply chain management. International Journal of Operations \& Production Management, 37(1), 10-36.

Kane, G., Labianca, G. G., Borgatti, S. P., \& Alavi, M. (2014). What's different about social media networks? A framework and research agenda. MIS Quarterly. https://doi.org/10.1017/CBO9781107415324.004.

Kim, Y., Choi, T. Y., Yan, T., \& Dooley, K. (2011). Structural investigation of supply networks: A social network analysis approach. Journal of Operations Management, 29(3), 194-211.

Kumar, A., Singh, J. P., Dwivedi, Y. K., \& Rana, N. P. (2020). A deep multi-modal neural network for informative Twitter content classification during emergencies. Annals of Operations Research. https:// doi.org/10.1007/s10479-020-03514-x.

Lagrosen, S. (2005). Customer involvement in new product development: A relationship marketing perspective. European Journal of Innovation Management. https://doi.org/10.1108/14601060510627803.

Lam, H. K. S., Yeung, A. C. L., \& Cheng, T. C. E. (2016). The impact of firms' social media initiatives on operational efficiency and innovativeness. Journal of Operations Management, 47-48, $28-43$.

Lau, R. Y. K., Li, C., \& Liao, S. S. Y. (2014). Social analytics: Learning fuzzy product ontologies for aspectoriented sentiment analysis. Decision Support Systems. https://doi.org/10.1016/j.dss.2014.05.005.

Leonardi, P. M. (2014). Social media, knowledge sharing, and innovation: Toward a theory of communication visibility. Information Systems Research. https://doi.org/10.1287/isre.2014.0536.

Levina, N., \& Arriaga, M. (2014). Distinction and status production on user-generated content platforms: Using Bourdieu's theory of cultural production to understand social dynamics in online fields. Information Systems Research. https://doi.org/10.1287/isre.2014.0535.

Levitt, T. (1985). Exploit the product life cycle. Harvard Business Review. https://doi.org/10.2139/ssrn.3832 42.

Light, D. W., Berger, P. L., \& Luckmann, T. (1967). The social construction of reality: A treatise in the sociology of knowledge. Sociological Analysis. https://doi.org/10.2307/3710424.

Lin, X., \& Germain, R. (2004). Antecedents to customer involvement in product development: Comparing US and Chinese firms. European Management Journal. https://doi.org/10.1016/j.emj.2004.01.009. 
Lin, Y., \& Zhou, L. (2011). The impacts of product design changes on supply chain risk: A case study. International Journal of Physical Distribution and Logistics Management, 41(2), 162-186.

Lincoln, Y. S., \& Guba, E. G. (1990). Judging the quality of case study reports. Internation Journal of Qualitative Studies in Education, 3(1), 53-59.

Lycett, M. (2013). 'Datafication': Making sense of (big) data in a complex world. European Journal of Information Systems, 22(4), 381-386.

Majumdar, A., \& Bose, I. (2019). Do tweets create value? A multi-period analysis of Twitter use and content of tweets for manufacturing firms. International Journal of Production Economics, 216, 1-11.

Malviya, R. K., \& Kant, R. (2016). Hybrid decision making approach to predict and measure the success possibility of green supply chain management implementation. Journal of Cleaner Production, 135, 387-409.

Maresh-Fuehrer, M. M., \& Smith, R. (2016). Social media mapping innovations for crisis prevention, response, and evaluation. Computers in Human Behavior. https://doi.org/10.1016/j.chb.2015.08.041.

Matthias, O., Fouweather, I., Gregory, I., \& Vernon, A. (2017). Making sense of big data—Can it transform operations management? International Journal of Operations \& Production Management, 37(1), 37-55.

McCarthy, I. P., Tsinopoulos, C., Allen, P., \& Rose-Anderssen, C. (2006). New product development as a complex adaptive system of decisions. Journal of Product Innovation Management. https://doi.org/10.1 111/j.1540-5885.2006.00215.x.

McKenna, B., Myers, M. D., \& Newman, M. (2017). Social media in qualitative research: Challenges and recommendations. Information and Organization. https://doi.org/10.1016/j.infoandorg.2017.03.001.

Mikkola, J. H., \& Skjøtt-Larsen, T. (2004). Supply-chain integration: Implications for mass customization, modularization and postponement strategies. Production Planning and Control. https://doi.org/10.1080/ 0953728042000238845.

Mirbabaie, M., and Zapatka, E. (2017). Sensemaking in social media crisis communication: A case study on the Brussels Bombings in 2016. In Proceedings of the 25th European conference on information systems.

Mishra, N., \& Singh, A. (2018). Use of twitter data for waste minimisation in beef supply chain. Annals of Operations Research. https://doi.org/10.1007/s10479-016-2303-4.

Myers, M., Avison, D., \& Boland, R. J. (2011). Information system use as a hermeneutic process. Qualitative Research in Information Systems. https://doi.org/10.4135/9781849209687.n12.

Nambisan, S. (2002). Designing virtual customer environments for new product development: Toward a theory. Academy of Management Review. https://doi.org/10.5465/AMR.2002.7389914.

Niesten, E., \& Stefan, I. (2019). Embracing the paradox of interorganizational value co-creation-Value capture: A literature review towards paradox resolution. International Journal of Management Reviews, 21(2), 231-255.

Ogawa, S., \& Piller, F. T. (2006). Reducing the risks of new product development. MIT Sloan Management Review, 47(2), 65.

Panagiotopoulos, P., Barnett, J., Bigdeli, A. Z., \& Sams, S. (2016). Social media in emergency management: Twitter as a tool for communicating risks to the public. Technological Forecasting and Social Change. https://doi.org/10.1016/j.techfore.2016.06.010.

Pang, B., \& Lee, L. (2009). Opinion mining and sentiment analysis. Computational Linguistics. https://doi. org/10.1162/coli.2009.35.2.311.

Piller, F. T., \& Walcher, D. (2006). Toolkits for idea competitions: A novel method to integrate users in new product development. $R$ and D Management. https://doi.org/10.1111/j.1467-9310.2006.00432.x.

Poetz, M. K., \& Schreier, M. (2012). The value of crowdsourcing: Can users really compete with professionals in generating new product ideas? Journal of Product Innovation Management. https://doi.org/10.1111/j. 1540-5885.2011.00893.x.

Popescu, A. M., \& Etzioni, O. (2007). Extracting product features and opinions from reviews. Natural Language Processing and Text Mining. https://doi.org/10.1007/978-1-84628-754-1_2.

Prahinski, C., \& Benton, W. C. (2004). Supplier evaluations: Communication strategies to improve supplier performance. Journal of Operations Management, 22(1), 39-62.

Qiu, G., Liu, B., Bu, J., \& Chen, C. (2011). Opinion word expansion and target extraction through double propagation. Computational Linguistics. https://doi.org/10.1162/coli_a_00034.

Quan, C., \& Ren, F. (2014). Unsupervised product feature extraction for feature-oriented opinion determination. Information Sciences. https://doi.org/10.1016/j.ins.2014.02.063.

Queiroz, M. M., \& Telles, R. (2018). Big data analytics in supply chain and logistics: An empirical approach. The International Journal of Logistics Management, 29(2), 767-783.

Rad, A. A., Jalali, M. S., \& Rahmandad, H. (2018). How exposure to different opinions impacts the life cycle of social media. Annals of Operations Research. https://doi.org/10.1007/s10479-017-2554-8. 
Ramanathan, U., Subramanian, N., \& Parrott, G. (2017). Role of social media in retail network operations and marketing to enhance customer satisfaction. International Journal of Operations \& Production Management, 37(1), 105-123.

Rehman, M. H. U., Chang, V., Batool, A., Wah, T. Y., ur Rehman, M. H., Chang, V., et al. (2016). Big data reduction framework for value creation in sustainable enterprises. International Journal of Information Management, 36(6), 917-928.

Revilla, E., \& Knoppen, D. (2015). Building knowledge integration in buyer-supplier relationships. International Journal of Operations \& Production Management, 35(10), 1408-1436.

Romero, D., \& Molina, A. (2011). Collaborative networked organisations and customer communities: Value co-creation and co-innovation in the networking era. Production Planning and Control. https://doi.org/ 10.1080/09537287.2010.536619.

Rozenfeld, B., \& Feldman, R. (2011). Unsupervised lexicon acquisition for HPSG-based relation extraction. IJCAI International Joint Conference on Artificial Intelligence. https://doi.org/10.5591/978-1-57735-51 6-8/IJCAI11-316.

Schilling, M. A., \& Hill, C. W. L. (1998). Managing the new product development process: Strategic imperatives. Academy of Management Executive. https://doi.org/10.5465/ame.1998.1109051.

See-To, E. W., \& Ngai, E. W. (2018). Customer reviews for demand distribution and sales nowcasting: A big data approach. Annals of Operations Research, 270(1-2), 415-431.

Singh, A., Shukla, N., \& Mishra, N. (2018). Social media data analytics to improve supply chain management in food industries. Transportation Research Part E: Logistics and Transportation Review. https://doi.org/ 10.1016/j.tre.2017.05.008.

Singh, J. P., Dwivedi, Y. K., Rana, N. P., Kumar, A., \& Kapoor, K. K. (2019). Event classification and location prediction from tweets during disasters. Annals of Operations Research. https://doi.org/10.1007/s1047 9-017-2522-3.

Singh, J. P., Irani, S., Rana, N. P., Dwivedi, Y. K., Saumya, S., \& Roy, P. K. (2017). Predicting the 'helpfulness' of online consumer reviews. Journal of Business Research, 70, 346-355.

Soukhoroukova, A., Spann, M., \& Skiera, B. (2012). Sourcing, filtering, and evaluating new product ideas: An empirical exploration of the performance of idea markets. Journal of Product Innovation Management. https://doi.org/10.1111/j.1540-5885.2011.00881.x.

Stevens, G., Burley, J., \& Divine, R. (2003). Creativity business discipline = higher profits faster from new product development. Journal of Product Innovation Management. https://doi.org/10.1111/1540-5885. 1650455 .

Stieglitz, S., \& Dang-Xuan, L. (2013). Social media and political communication: A social media analytics framework. Social Network Analysis and Mining. https://doi.org/10.1007/s13278-012-0079-3.

Taboada, M., Brooke, J., Tofiloski, M., Voll, K., \& Stede, M. (2011). Lexicon-based methods for sentiment analysis. Computational Linguistics. https://doi.org/10.1162/COLI_a_00049.

Takeuchi, H., \& Nonaka, I. (1986). The new product development game. Harvard Business Review, 64(1), $137-146$.

Trabucchi, D., \& Buganza, T. (2019). Data-driven innovation: Switching the perspective on big data. European Journal of Innovation Management. https://doi.org/10.1108/EJIM-01-2018-0017.

Tsinopoulos, C., \& Mena, C. (2015). Supply chain integration configurations: Process structure and product newness. International Journal of Operations \& Production Management, 35(10), 1437-1459.

Van Oorschot, K., Sengupta, K., Akkermans, H., \& Van Wassenhove, L. (2010). Get fat fast: Surviving stagegates in NPD. Journal of Product Innovation Management. https://doi.org/10.1111/j.1540-5885.2010.0 0754.x.

Vatrapu, R., Mukkamala, R. R., Hussain, A., \& Flesch, B. (2016). Social set analysis: A set theoretical approach to big data analytics. IEEE Access, 4, 2542-2571.

Veryzer, R. W. (1998). Discontinuous innovation and the new product development process. Journal of Product Innovation Management. https://doi.org/10.1111/1540-5885.1540304.

Wagner, S. M., Bode, C., \& Koziol, P. (2009). Supplier default dependencies: Empirical evidence from the automotive industry. European Journal of Operational Research, 199(1), 150-161.

Walsham, G. (1995). The emergence of interpretivism in IS research. Information Systems Research, 6(4), 376-394.

Wei, Z., Yi, Y., \& Guo, H. (2014). Organizational learning ambidexterity, strategic flexibility, and new product development. Journal of Product Innovation Management, 31(4), 832-847.

Weick, K. E. (1995). Sensemaking in organizations (Vol. 3). Thousand Oaks: Sage.

Weick, K. E., Sutcliffe, K. M., \& Obstfeld, D. (2005). Organizing and the process of sensemaking. Organization Science. https://doi.org/10.1287/orsc.1050.0133. 
Wu, K.-J.-J., Liao, C.-J.-J., Tseng, M.-L.-L., Lim, M. K., Hu, J., \& Tan, K. (2015). Toward sustainability: Using big data to explore the decisive attributes of supply chain risks and uncertainties. Journal of Cleaner Production, 142, 663-676.

Yan, T., \& Azadegan, A. (2017). Comparing interorganizational new product development strategies: Buy or ally; supply-chain or non-supply-chain partners? International Journal of Production Economics, 183, 21-38.

Yan, T., \& Wagner, S. M. (2017). Do what and with whom? Value creation and appropriation in inter organizational new product development projects. International Journal of Production Economics, 191, 1-14.

Yin, R. K. (2009). How to do better case studies. In: Bickman, L. \& Rog, D.J (Eds.), The SAGE handbook of applied social research methods, USA.

Zeng, D., Chen, H., Lusch, R., \& Li, S. H. (2010). Social media analytics and intelligence. IEEE Intelligent Systems. https://doi.org/10.1109/MIS.2010.151.

Zhan, Y., Tan, K. H., Li, Y., \& Tse, Y. K. (2018). Unlocking the power of big data in new product development. Annals of Operations Research, 270(1-2), 577-595.

Zhan, Y., Tan, K. H., Chung, L., Chen, L., \& Xing, X. (2020). Leveraging social media in new product development: Organisational learning processes, mechanisms and evidence from China. International Journal of Operations \& Production Management. https://doi.org/10.1108/IJOPM-04-2019-0318.

Zhou, Q., Xu, Z., \& Yen, N. Y. (2019). User sentiment analysis based on social network information and its application in consumer reconstruction intention. Computers in Human Behavior. https://doi.org/10.10 16/j.chb.2018.07.006.

Publisher's Note Springer Nature remains neutral with regard to jurisdictional claims in published maps and institutional affiliations.

\section{Affiliations}

\section{Mihalis Giannakis ${ }^{1} \cdot$ Rameshwar Dubey $^{2}$ D $\cdot$ Shishi Yan $^{3} \cdot$ Konstantina Spanaki $^{4}$. Thanos Papadopoulos 5}

$\bowtie$ Rameshwar Dubey

r.dubey@ljmu.ac.uk

Mihalis Giannakis

mgiannakis@audencia.com

Shishi Yan

S.Yan.1@warwick.ac.uk

Konstantina Spanaki

K.Spanaki@lboro.ac.uk

Thanos Papadopoulos

A.Papadopoulos@kent.ac.uk

1 Audencia Business School, Nantes, France

2 Liverpool Business School, Liverpool John Moores University, Liverpool, UK

3 University of Warwick, Coventry, UK

4 School of Business and Economics, Loughborough University, Loughborough, UK

5 Kent Business School, University of Kent, Canterbury, UK 